Check for updates

Cite this: Mater. Chem. Front., 2020, 4, 113

Received 31st August 2019, Accepted 1st October 2019 DOI: $10.1039 / c 9 q m 00555 b$

rsc.li/frontiers-materials

\section{Tailored covalent organic frameworks by post-synthetic modification}

\author{
Huimin Ding, Arindam Mal and Cheng Wang (D) *
}

Covalent organic frameworks (COFs), constructed by strong covalent bonds based on reticular chemistry, hold great promise in diverse applications. Manipulating COFs with desired functional properties is of paramount significance. However, the standard solvothermal synthetic methodologies for COF synthesis do not always allow direct incorporation of functional groups into frameworks, due to the incompatibility with the building blocks or reaction conditions. In this regard, alternative approaches for post-synthetic modification (PSM) on a pre-established network provide an opportunity for tuning the functional properties of COFs while maintaining a fundamental framework structure. This review describes recent advances and scientific challenges in the area of post-synthetic methodologies to tailor the properties of COFs. Two different major PSM techniques, namely, covalent PSM and post-synthetic metal functionalization, will be discussed.

\section{Introduction}

Covalent organic frameworks (COFs) are a class of porous, crystalline materials made up of organic building units linked by strong covalent bonds to generate long-range ordered twodimensional $(2 \mathrm{D})^{1-5}$ or three-dimensional $(3 \mathrm{D})^{6-10}$ network structures. The inherent characteristic structural features of COFs, such as pre-designable functionality and modular porous nature, have endowed this emerging material with interesting applications in gas storage and separation, ${ }^{11-13}$ catalysis, ${ }^{14-17}$ chemical sensing, ${ }^{18-22}$ optoelectronics, ${ }^{23-26}$ proton

Sauvage Center for Molecular Sciences and Hubei Key Lab on Organic and Polymeric Optoelectronic Materials, College of Chemistry and Molecular Sciences, Wuhan University, Wuhan 430072, China. E-mail: chengwang@whu.edu.cn conductivity, ${ }^{27-29}$ energy storage $\mathrm{e}^{30-33}$ and so on. Therefore, the incorporation of novel functional moieties into COFs, which can allow the resulting material to have the desired properties, has gained much attention over the past decade. However, sometimes, these functional groups could not be directly incorporated into the framework through the routine 'bottom-up' solvothermal synthetic strategy, due to the incompatibility with the building blocks or reaction conditions. Consequently, it is highly desirable to develop a simple and efficient method to overcome this issue.

Post-synthetic modification (PSM),${ }^{34}$ which can introduce new functional groups on a pre-established COF skeleton through chemical transformation or modification while retaining the underlying topology, provides a powerful method to construct functional COFs. Firstly, the characteristic strong covalent

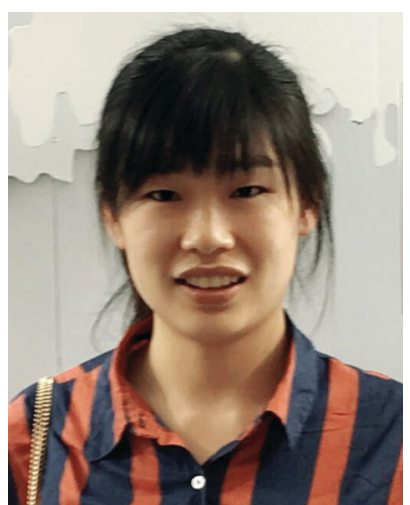

Huimin Ding
Huimin Ding received her BS in Chemistry from Qufu Normal University in 2012. She pursued her PhD study under the supervision of Prof. Cheng Wang at Wuhan University and obtained her PhD degree in 2018, where she is currently carrying out postdoctoral research on $3 D$ covalent organic frameworks.

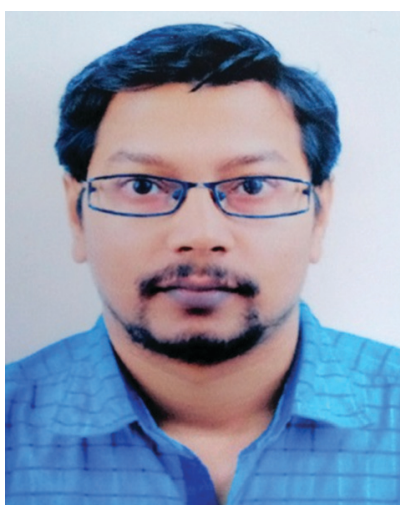

Arindam Mal
Dr Arindam Mal completed his Master of Science at Indian Institute of Technology, Kharagpur (India) and PhD from CSIR-National Institute for Interdisciplinary Science and Technology (India). He is currently working as a postdoctoral research scholar of Wuhan University in Prof. Cheng Wang's research group under an international postdoctoral exchange fellowship program. His research focuses on $3 D$ covalent organic frameworks. 
linkages in COFs offer structural robustness necessary for PSM techniques. Secondly, the judicious selection of building blocks allows the integration of linkers with pendant reactive groups or metal binding sites into COFs in predetermined positions for PSM. Thirdly, the high crystallinity of COFs endows the ability to implement a PSM process and results in materials which can be well characterized. Thanks to the efforts of many groups, significant progress has been achieved in constructing COFs with structural diversity and complexity via PSM strategies.

In recent times, a few interesting reviews on PSM of COFs have been reported, ${ }^{35,36}$ indicating the importance of this research area. However, a concise discussion covering the most important achievements of PSM strategies with more focused classifications was still unavailable. In this review, we summarize the research progress in PSM of COFs over the past decade, by classifying the functionalization strategy into two parts, covalent PSM and post-synthetic metal functionalization. According to different modification sites, the former can be further subdivided as the covalent PSM of linkers and post-synthetic conversion of linkages, where the latter can be understood via coordinating with the functional groups on the backbone. Lastly, a brief perspective on the challenges and possibilities of this field will be covered.

\section{Covalent post-synthetic modification}

Covalent PSM of COFs is considered to be the most significant strategy, which involves functional group inter-conversion through different covalent reactions. In this part, we will summarize the covalent PSM in two different sections, covalent PSM of linkers and linkages.

\subsection{Covalent post-synthetic modification of linkers}

Starting from a COF with predesigned reactive groups, functional moieties can be covalently attached to the COF backbone

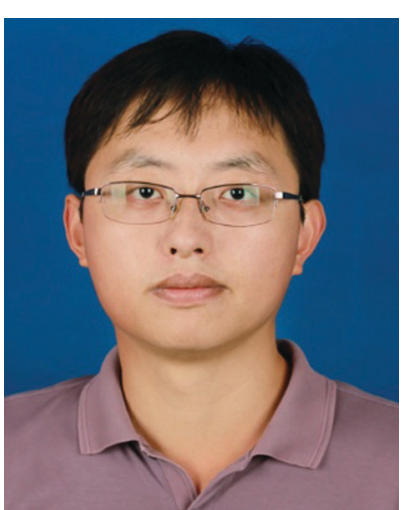

Cheng Wang
Dr Cheng Wang obtained his BSc degree (2003) from Wuhan University and his $P h D$ degree (2008) in organic chemistry from Institute of Chemistry, Chinese Academy of Sciences, under the supervision of Professor Deqing Zhang and Academician Professor Daoben Zhu. Following postdoctoral research with Professor Sir J. Fraser Stoddart in Northwestern University, he returned to China on March 2012 and started his new position as a full professor at College of Chemistry and Molecular Sciences, Wuhan University. His research focuses on functional microporous materials, including covalent organic frameworks and metal-organic frameworks. by reacting with linkers while retaining the original framework. In this part, we present the main organic reactions used for COF PSM functionalization.

2.1.1. Click reaction. Click reaction is considered to be one of the most widely used PSM reactions due to high specificity, quantitative conversion yield and convenient synthetic protocols. ${ }^{37}$ In a very first report, Jiang and co-workers tailored the functionalities of a boronate ester framework with pendant alkynyl groups via a post-synthetic copper(I)-catalyzed alkyne-azide cycloaddition (CuAAC) click reaction. ${ }^{38}$ Typically, in the presence of a CuI catalyst, after reacting with alkynyl compounds in anhydrous $N, N^{\prime}$-dimethylacetamide at $50{ }^{\circ} \mathrm{C}$ for $24 \mathrm{~h}$, the corresponding modified COFs were obtained in quantitative yield. Thereby, the gas-sorption selectivity of $\mathrm{CO}_{2}$ over $\mathrm{N}_{2}$ has been substantially controlled by the density of desired functional groups in the pores. Later on, by using the same reaction, they successfully immobilized the $1,2-\left(4^{\prime}-\right.$ propiolyloxycyclohexno) fullerene onto the channel walls of COFs. $^{39}$

Furthermore, to avoid the instability of boronate ester COFs, Jiang and co-workers synthesized an ultra-stable iminebased COF (TPB-DMTP) with alkyne groups. ${ }^{40}$ By performing a post-synthetic CuAAC click reaction, organocatalytic sites were anchored onto the pore channels to generate $[(\boldsymbol{S})-\mathbf{P y}]_{X_{\%}}{ }^{-}$ TPB-DMTP-COFs, which can be used as an efficient heterogeneous catalyst in Michael addition reaction (Fig. 1). For example, the quantitative conversion of cyclohexanone and $\beta$-nitrostyrene was achieved in 12 hours with enantioselectivity (92\% e.e.) and diastereoselectivity (90/10 d.r.). Very recently, Shustova and co-workers integrated corannulene $\pi$-bowls $(\pi \mathrm{Bs})$ into COFs by using this reaction while preserving porosity and crystallinity. ${ }^{41}$ Interestingly, the $\pi$ Bs-integrated COF exhibited 10000 -fold enhancement in conductivity compared to the initial framework.

Another type of click reaction, the thiol-ene reaction, has also been extensively applied in PSM of COFs. Dichtel and co-workers have demonstrated that a functionalized 3D COF can be constructed by the combination of a tandem truncationfunctionalization strategy with thiol-ene reaction. ${ }^{42}$ Firstly, via co-condensation of tetrahedral and truncated trigonal monomers, a boroxine-linked COF has been synthesized with a $22 \%$ allyl-loading throughout the lattice. Succeedingly, the as-prepared allyl functionalized COF has been subjected to quantitative thiol-ene reaction with propanethiol to produce an alkane-thiol modified COF, maintaining the crystallinity and permanent porosity. In another work, Ma and co-workers synthesized a vinyl-functionalized COF (COF-V) and subsequently modulated the structure and function via the same reaction (Fig. 2). ${ }^{43}$ The resulting sulfur-based COF-S-SH exhibited a strong binding affinity for $\mathrm{Hg}^{2+}$, with high uptake capacity of $1350 \mathrm{mg} \mathrm{g}^{-1}$. This performance was better than the previously reported thiol and thioether-functionalized adsorbents for mercury removal, which can be attributed to densely populated thiol groups (over 90\%) within ordered mesopores. Very recently, they integrated perfluoroalkyl groups on COF-V for altering its water-repellent properties. ${ }^{44}$ Although only $4 \%$ of the vinyl groups were involved in the PSM process, 


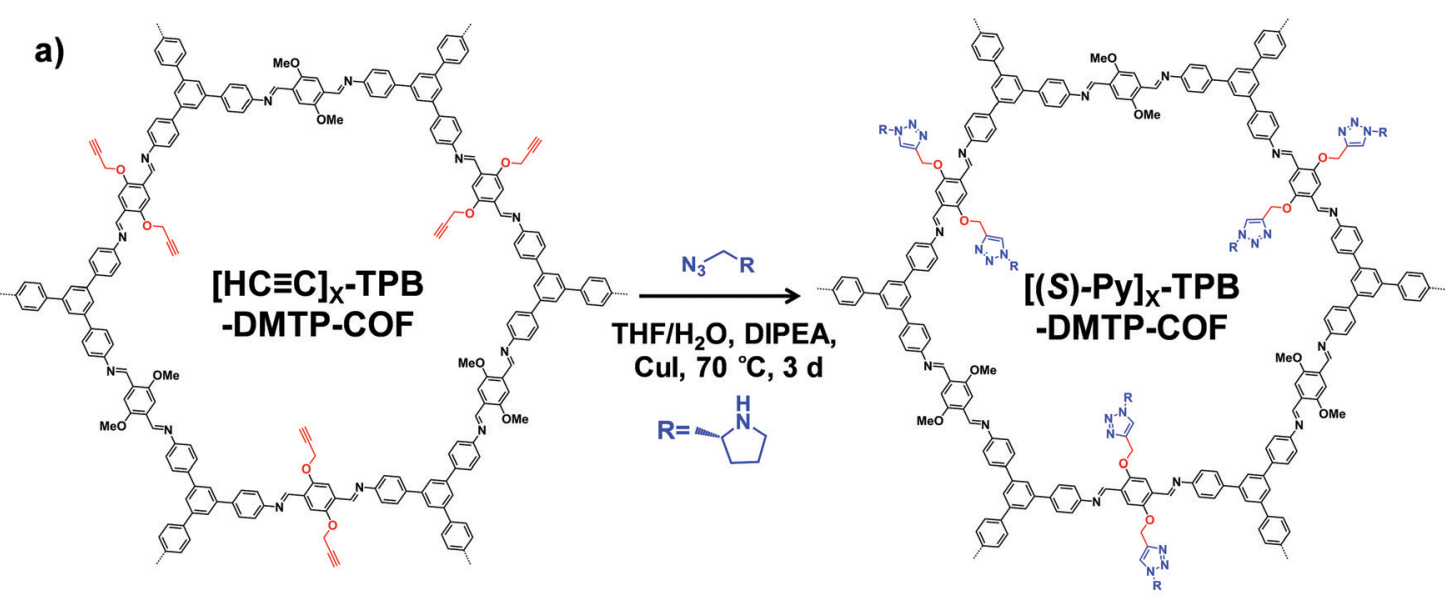

b)
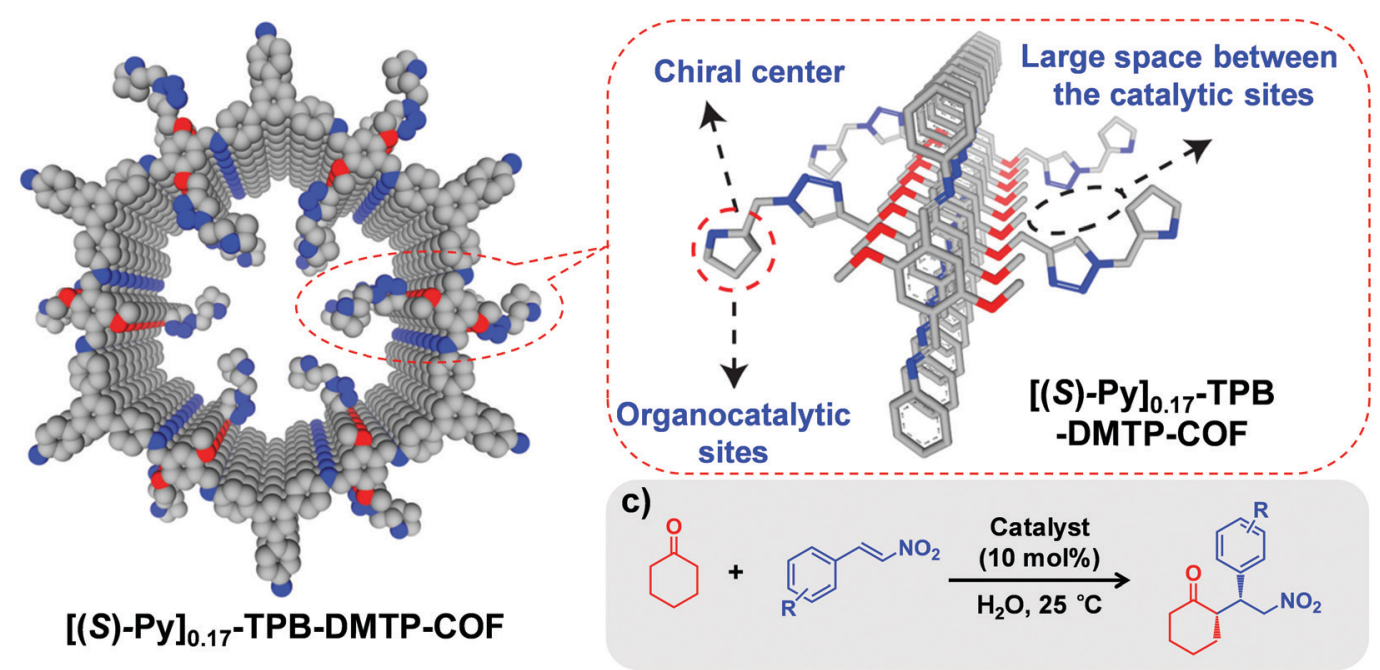

Fig. 1 (a) Post-synthetic modification of [HC $\equiv \mathrm{C}_{x}$-TPB-DMTP-COFs with chiral functional groups via a CuAAC reaction. (b) Channel-wall structure of $[(S)-P y]_{0.17}-$ TPB-DMTP-COF. The space between the catalytic sites is required for the face-on stacking of nitrostyrene over the catalytic sites and plays a role in controlling the activity of the catalysts. (c) $\left[\mathrm{HC} \equiv \mathrm{C}_{X}\right.$-TPB-DMTP-COFs can be used as catalysts in asymmetric Michael reactions. Reproduced from ref. 40, with permission from Springer Nature, Copyright 2015.

the small number of perfluoroalkyl groups on the resulting COF significantly increased the hydrophobicity, with a static water contact angle of about $167^{\circ}$.

2.1.2. Transformation of hydroxyl groups. The hydroxyl groups can be conveniently transformed into other groups through different types of reactions, such as esterification, alkylation, substitution reaction and so on. The construction of -OH based COFs and their further functionalization through the PSM approach have also gained much interest.

Jiang and co-workers reported the design and synthesis of $[\mathrm{HO}]_{X \%}-\mathrm{H}_{2} \mathbf{P}-\mathrm{COF}$ with hydroxyl groups which could react with succinic anhydride to generate a series of COFs $\left(\left[\mathrm{HO}_{2} \mathrm{C}\right]_{X \%}-\mathrm{H}_{2} \mathbf{P}-\right.$ COFs) bearing a tunable amount of carboxylic acid on the pore walls. ${ }^{45}$ The decreased pore size, together with carboxylic acid groups on $\left[\mathrm{HO}_{2} \mathbf{C}\right]_{\mathrm{X} \%}-\mathbf{H}_{2} \mathbf{P}$-COFs enabled the superior performance of $\mathrm{CO}_{2}$ adsorption. Later on, Fang and co-workers reported a hydroxy-functionalized 3D COF which can be used to construct a carboxy-functionalized COF that exhibited selective and high metal-loading capability $\left(0.71 \mathrm{mmol} \mathrm{g}{ }^{-1} / \mathrm{Nd}^{3+}\right.$, $0.72 \mathrm{mmol} \mathrm{g}^{-1} / \mathrm{Sr}^{2+}$ and $\left.4.86 \mathrm{mmol} \mathrm{g}{ }^{-1} / \mathrm{Fe}^{3+}\right){ }^{46}$
Gao and co-workers have controllably synthesized a series of COFs with various contents of ester functionalities via a post-synthetic acylation reaction of the hydroxyl groups and carbonyl chloride. ${ }^{47}$ The attached $\mathrm{CO}_{2}$-philic units and $\mathrm{N}_{2}$-phobic units, i.e., 4-phenylazobenzoyl chloride and stilbenecarbonyl chloride could significantly affect the $\mathrm{CO}_{2}$ uptake and $\mathrm{CO}_{2} / \mathrm{N}_{2}$ selectivity of the COFs. Very recently, the same group synthesized a sulfonic acid-based COF via an etherification reaction with the phenolic hydroxyl moieties of the COF and 1,3-propane sultone. ${ }^{48}$ The modified COF having charged sulfonic acid groups was able to capture metal ions through the ion exchange process. In addition, the obtained ionic COF showed good catalytic activity in the epoxidation of olefins, with yields of $83 \%, 80 \%$, and $62 \%$ for cyclohexene, cyclooctene, and 1-hexene, respectively.

The hydroxyl groups present in COFs can also be applied in a nucleophilic substitution or addition reaction with halides and isothiocyanate, respectively. Gao and associates have demonstrated that phenol groups of pyrene-based COFs could take part in a post-synthetic Williamson ether reaction with 


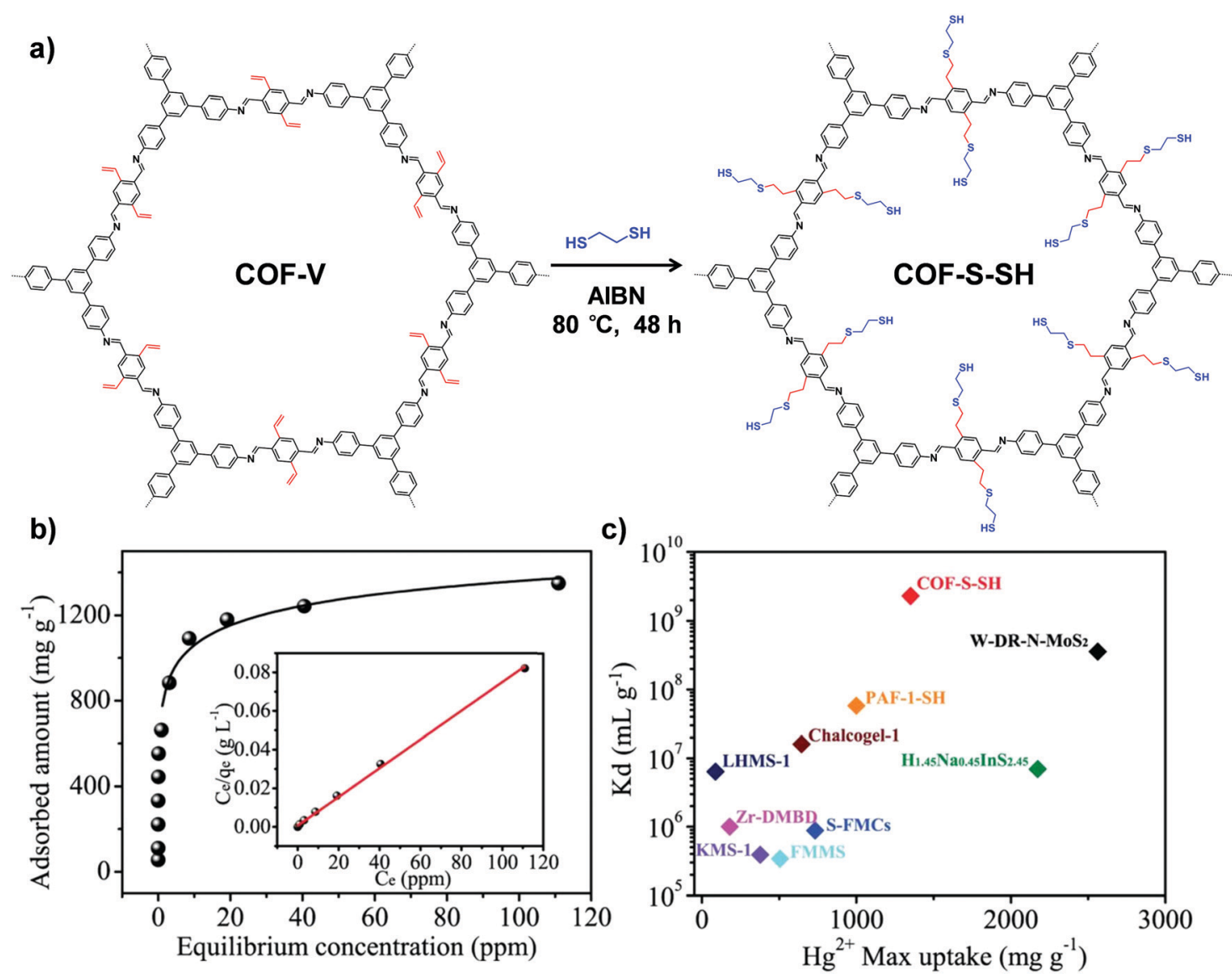

Fig. 2 (a) Post-synthetic modification of COF-V via a thiol-ene click reaction. (b) $\mathrm{Hg}^{2+}$ adsorption isotherm for COF-S-SH. Inset shows the linear regression by fitting the equilibrium data with the Langmuir adsorption model. (c) Comparison of $\mathrm{Hg}^{2+}$ saturation uptake amount and $K_{\mathrm{d}}$ value for COF-S-SH with those of benchmark porous materials. Reproduced from ref. 43, with permission from American Chemical Society, Copyright 2017.

(2-bromoethyl)triethylammonium bromide. $^{49}$ The obtained ionic COF facilitated excellent heterogeneous catalytic performance for the $N$-formylation reactions of different amines. For example, $N$-methylanilines with electron-donating or electronwithdrawing groups were converted into the corresponding formamides with isolated yields over $88 \%$.

Bein and co-workers grafted a fluorescent dye onto the framework of a hydroxyl-functionalized mesoporous COF by reacting with fluorescein-isothiocyanate (FITC). ${ }^{50}$ Even though the proportion of hydroxyl groups involved in a PSM process was low, the FITC-labelled COF exhibited strong green fluorescence which was absent in the case of the initial COF.

2.1.3. Transformation of nitriles. Very recently, Yaghi and co-workers have found that the nitrile groups of an as-synthesized dioxin-linked COF-316 could be partially converted to amide or amidoxime under basic conditions ( $\mathrm{NaOH}$ or $\left.\mathrm{NH}_{2} \mathrm{OH}\right)$, yielding COF-316-CONH ${ }_{2}$ and COF-316-C(NOH) $\mathbf{N H}_{2}$, respectively (Fig. 3). ${ }^{51}$ PXRD patterns revealed that the obtained COFs maintained their crystallinity. A similar pathway has been adopted by Ma and co-workers to achieve oxime-modified COFs. ${ }^{52}$ It is worth mentioning that the final amides, amidoxime or oximemodified COFs provide great potential for uranium sequestration. In another work, Feng et al. have transformed the nitrile groups of an $\mathrm{sp}^{2}$-carbon-linked $2 \mathrm{D}$ COF into carboxylic acid moieties under basic conditions. ${ }^{53}$ The modified COF showed higher surface polarity and better solution processability than the original framework.

2.1.4. Transformation of nitro groups. Bein and co-workers achieved the post-synthetic reduction of pendant nitro groups in a chemically stable COF to generate a new framework bearing amine functional moieties. ${ }^{54}$ Moreover, the resulting COF could further undergo an aminolysis reaction in the presence of acetic anhydride, yielding an amide integrated COF. Interestingly, due to distinct chemical pore environments, the amine and amide functionalized COFs showed enhanced affinity towards lactic acid compared to the pristine COF.

2.1.5. Diels-Alder cycloaddition reaction. Banerjee and co-workers have developed a Diels-Alder cycloaddition reaction for PSM of an anthracene-containing COF (DaTp) (Fig. 4). ${ }^{55}$ After the reaction with excessive $N$-hexylmaleimide at $160{ }^{\circ} \mathrm{C}$, DaTp eventually lost its interlayer $\pi-\pi$ stacking interactions, leading to the formation of exfoliated DaTp CONs. Through layer by layer assembly, the exfoliated DaTp CONs formed selfstanding thin films at the air-water interface, owing to the synergistic effect between nonplanarity of anthracenes and the hydrophobicity of pendant hexyl groups. This work has not only 


\section{a)}
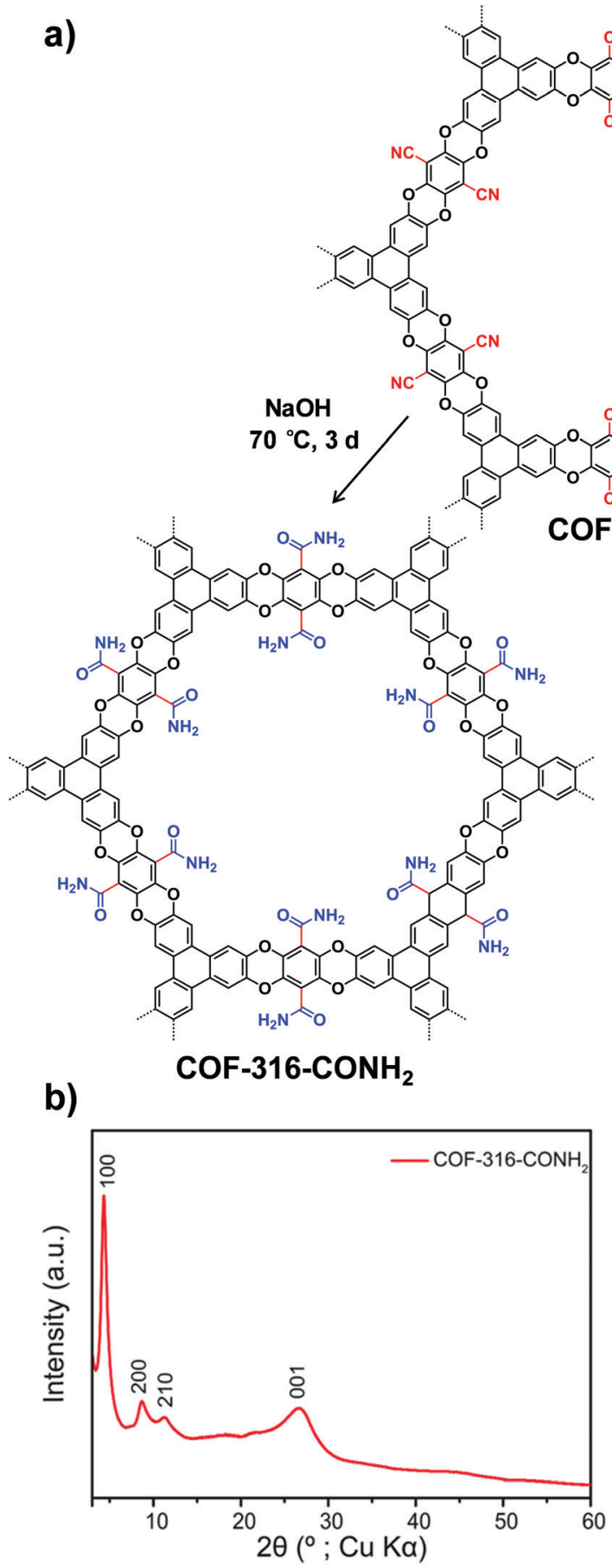

c)
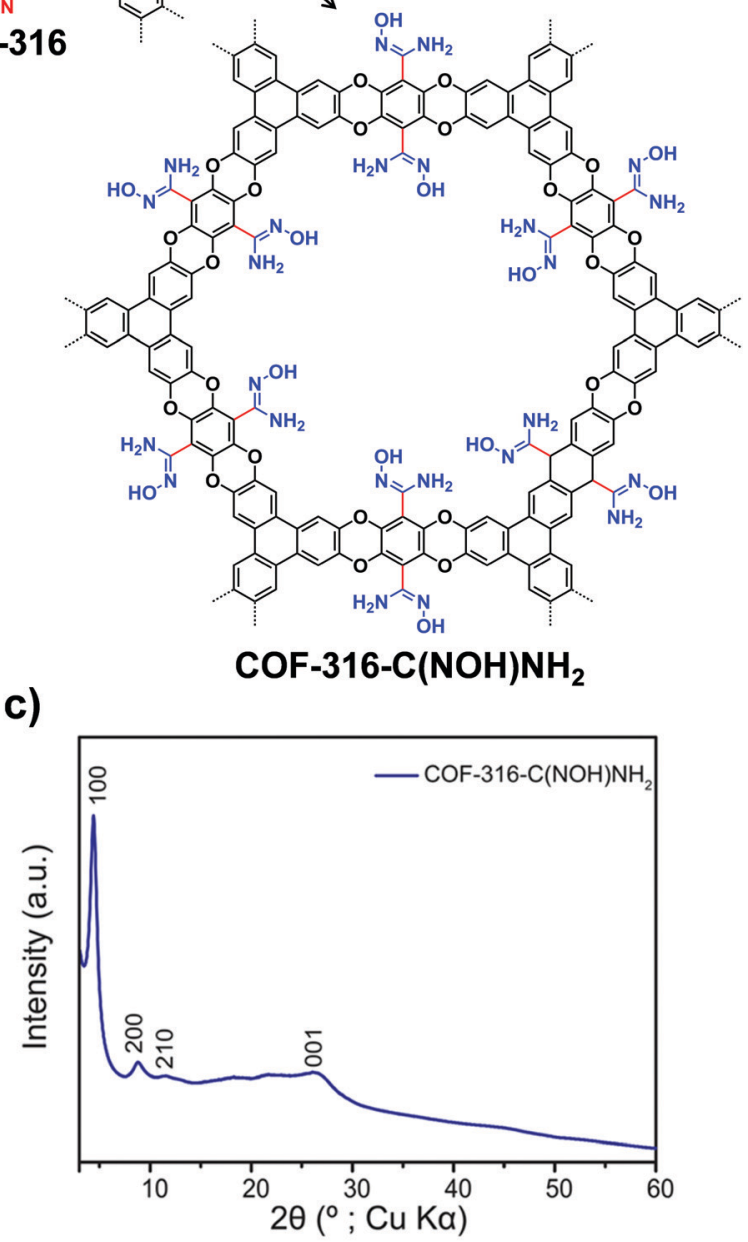

Fig. 3 (a) Transformation of the nitrile-functionalized COF-316 to amide-functionalized COF (COF-316-CONH ${ }_{2}$ ) and amidoxime-functionalized COF (COF-316-C(NOH) $\mathrm{NH}_{2}$ ). PXRD patterns: (b) COF-316-CONH ${ }_{2}$, (c) COF-316-C(NOH) $\mathbf{N H}_{2}$. Reproduced from ref. 51, with permission from American Chemical Society, Copyright 2018.

broadened the scope of covalent PSM reactions but also established a new strategy to fabricate self-standing COF thin films.

2.1.6. Inverse vulcanization. Awaga applied the inverse vulcanization strategy to modify the propynyl functionalized COF post-synthetically. ${ }^{56}$ The resulting sulfur modified COF can be utilized as a cathode for rechargeable lithiumsulfur batteries, with a capacity of $425 \mathrm{~mA} \mathrm{~h} \mathrm{~g}{ }^{-1}$ at a rate of $250 \mathrm{~mA} \mathrm{^{-1 }}$. Segura and Chen also successfully modified the vinyl functionalized COFs through inverse vulcanization to improve battery performance. ${ }^{57,58}$ For example, the inversevulcanized COF cathode exhibited a high initial capacity of $1400 \mathrm{~mA} \mathrm{~h} \mathrm{~g}^{-1}$ that was retained at $959 \mathrm{~mA} \mathrm{~h} \mathrm{~g}^{-1}$ after 100 cycles, owning to the synergistic effects of chemical sulfur fixation and physical sulfur encapsulation.

2.1.7. Deprotection reaction. Wang et al. constructed two chiral COFs with $N$-Boc protecting groups, ${ }^{59}$ which were converted 


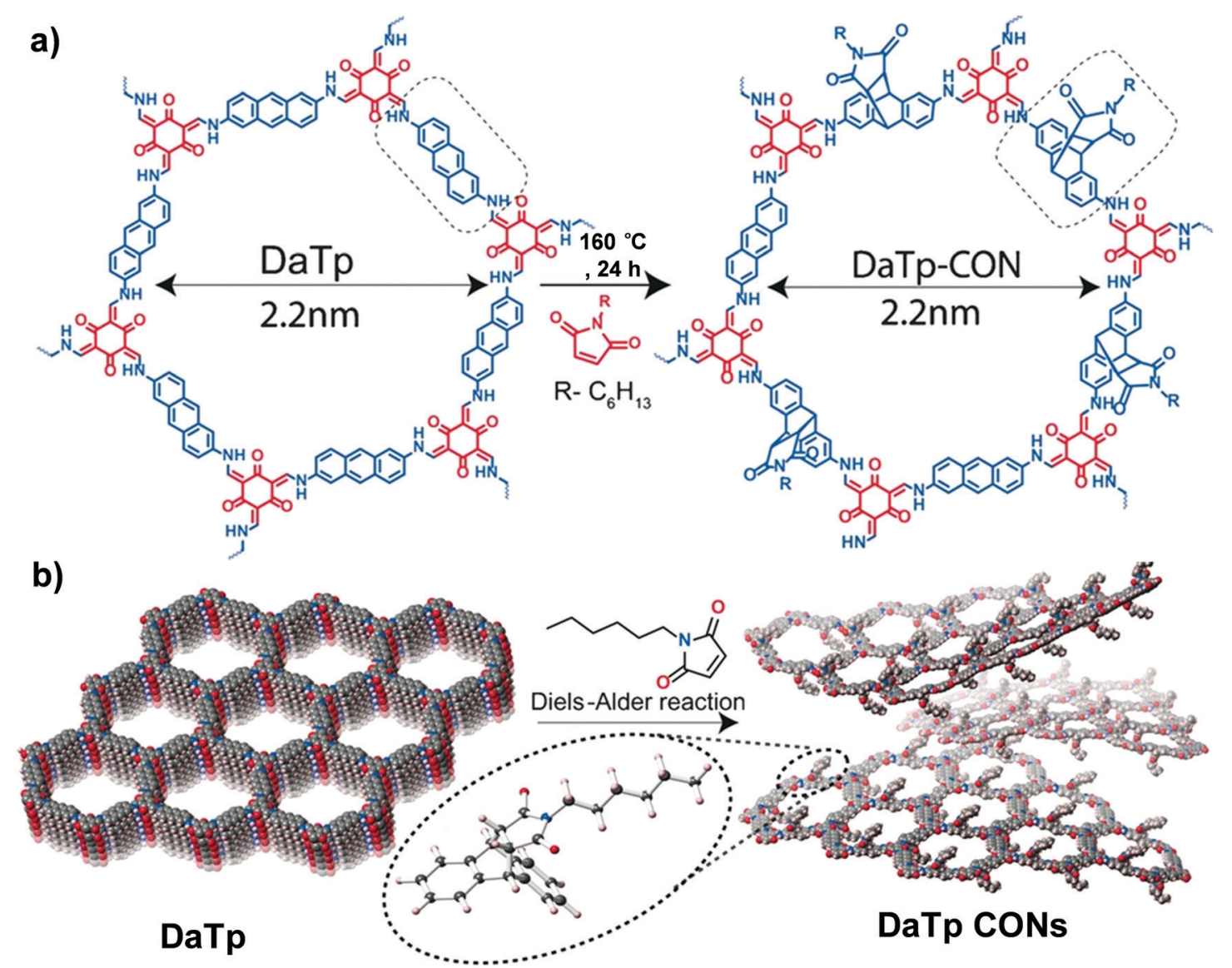

Fig. 4 (a) Diels-Alder cycloaddition reaction of DaTp with $N$-hexylmaleimide to afford DaTp CONs. (b) Schematic representation of the exfoliation process. Reproduced from ref. 55, with permission from John Wiley and Sons, Copyright 2016.

into chiral COFs with bare L-prolines thorough a post-synthetic heat-treatment. Interestingly, the resulting COFs exhibited excellent enantioselectivity in an asymmetric aldol reaction. In another work, Cui and co-workers have reported a series of 2D chiral COFs and applied the deprotection reaction to remove the inherent Boc- and Me-groups. ${ }^{60}$ Consequently, the resulting COFs with chiral pyrrolidine and imidazolidine moieties were employed as versatile organocatalysts in various asymmetric reactions including $\alpha$-aminooxylation, Aldol reactions and Diels-Alder reactions. For example, after the reaction of cyclohexanone with 4-nitrobenzaldehyde, the desired product was obtained with $92 \%$ e.e.

2.1.8. Post-synthetic linker exchange. As most COFs were constructed through dynamic covalent chemistry, the inherently dynamic nature of covalent bonds can allow them to undergo post-synthetic linker exchange. ${ }^{61-64}$ In 2017, Zhao and co-workers reported a benzidine containing COF (TP-COF-BZ), which can perform post-synthetic linker exchange with 1,4-diaminobenzene (Fig. 5). ${ }^{65}$ With increasing amounts of 1,4-diaminobenzene, the featured PXRD peaks of the new COF (TP-COF-DAB) increased, indicating the on-going COF to COF transformation. From the time-dependent PXRD experiments, the substitution reaction of the linkers occurred in the first half hour, leading to the disassociation of TP-COF-BZ. After extending the reaction time, the crystallinity of the desired TP-COF-DAB increased considerably. Recently, by using the same strategy, Han et al. also reported COF transformations from $3 \mathrm{D}$ to $3 \mathrm{D}$ and $3 \mathrm{D}$ to $2 \mathrm{D}$, with up to $89 \%$ and $78 \%$ exchange efficiency, respectively. ${ }^{66}$

\subsection{Post-synthetic conversion of linkages}

Besides the linkers, the linkages of COFs can also take part in a PSM reaction. However, only the imine-linked COFs have been successfully transformed to the corresponding modified COFs by several reactions. In this part, we will summarize the recent progress of this PSM conversion in detail.

2.2.1. Oxidation of imine linkages. In 2016, Yaghi and co-workers reported the first example of oxidation of iminelinked COFs to amide-linked COFs (Fig. 6). ${ }^{67}$ The solid-state conversion of imine to amide linkages was found to be quantitative while retaining the crystallinity and porosity. Remarkably, compared to the initial COF, the resulting amide-linked COFs exhibited enhanced stability after treatment with $12 \mathrm{M}$ $\mathrm{HCl}($ aq.) and $1 \mathrm{M} \mathrm{NaOH}($ aq.). Later on, Cui and co-workers utilized a similar technique to create an amide-linked 3D COF with enhanced chemical stability for chromatographic enantioseparation. ${ }^{68}$

2.2.2. Cycloaddition of imine linkages. Liu and co-workers reported the transformation of imine-linked COFs into ultrastable 


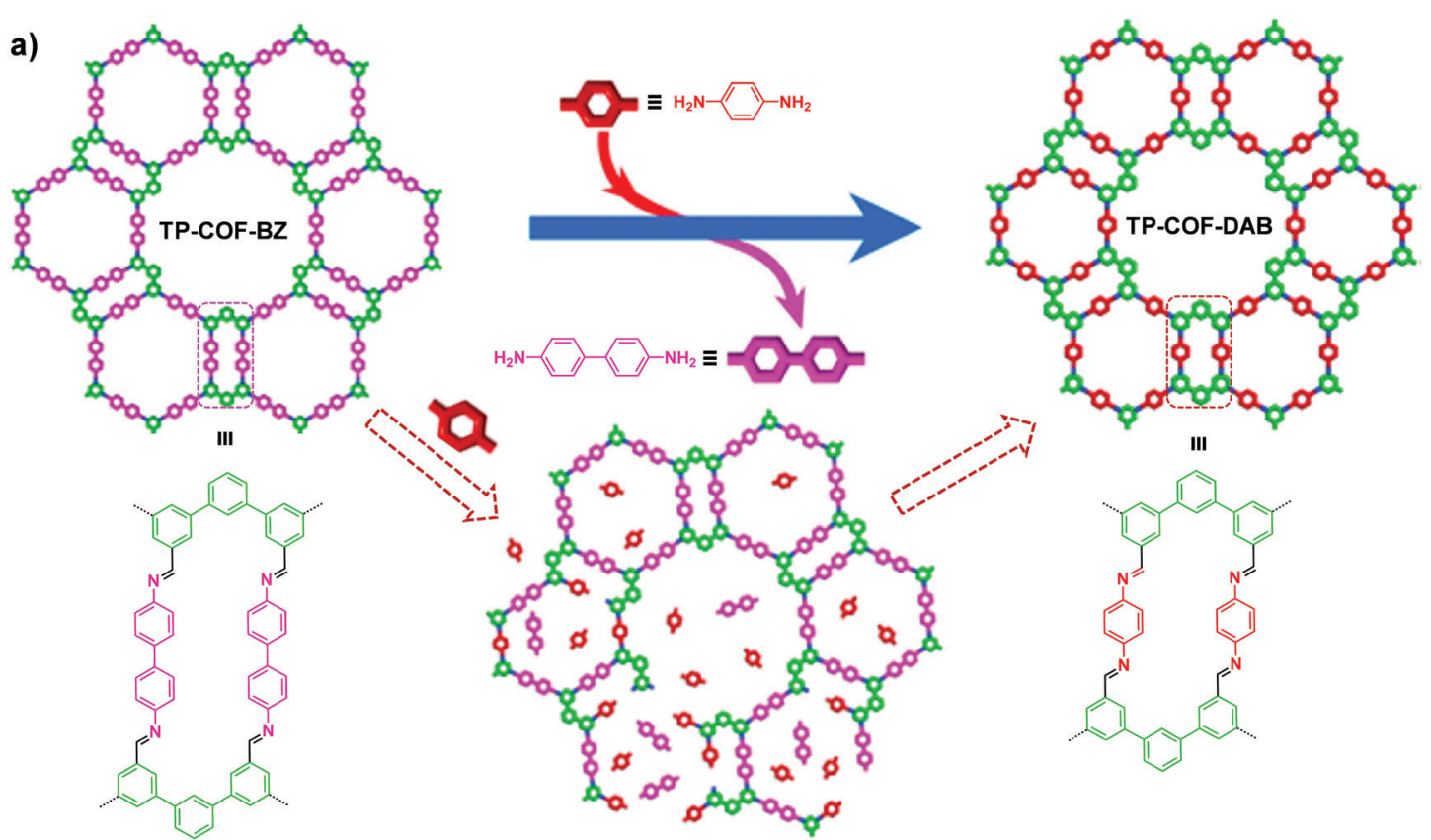

b)

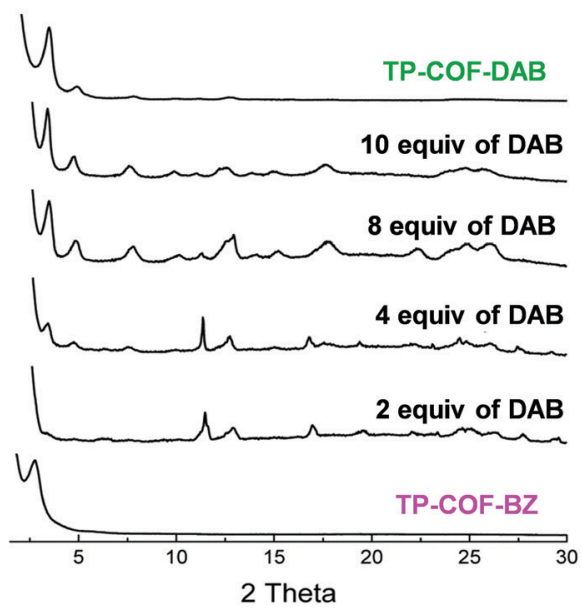

c)

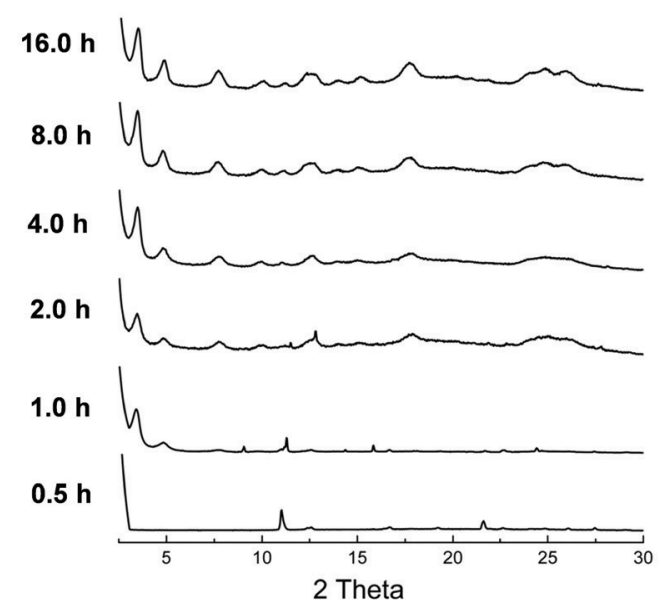

Fig. 5 (a) Synthesis of TP-COF-DAB by post-synthetic linker exchange and the proposed process for the in situ transformation of TP-COF-BZ into TP-COF-DAB in the presence of 1,4-diaminobenzene. (b) Transformation from TP-COF-BZ to TP-COF-DAB in different equivalents of 1,4-diaminobenzene for $72 \mathrm{~h}$ at $120{ }^{\circ} \mathrm{C}$ indicated by PXRD patterns. (c) Time-dependent PXRD patterns of the samples prepared by heating a mixture of TP-COF-BZ and 1,4-diaminobenzene (10 equiv.). Reproduced from ref. 65, with permission from American Chemical Society, Copyright 2017.

amine-linked COFs via the aza-Diels-Alder cycloaddition reaction (Fig. 7). ${ }^{69}$ After reacting with different arylalkynes bearing various functional groups, COF-1 was partially converted ( $\sim 20-30 \%$ conversion) to the corresponding quinoline-linked COF (MF-1). In the presence of strong mineral acid, superacid, etc., the modified MF-1 exhibited exceptional chemical stability, as confirmed by the retention of diffraction peaks. Notably, MF-1 showed controllable surface wettability with contact angle variation from $35^{\circ}$ to $155^{\circ}$.

2.2.3. Cascade cyclization-oxidation of imine linkages. Yaghi and co-workers have demonstrated the successful conversion from imine to thiazole and oxazole linkages in COFs. ${ }^{70}$ The initial COF reacted with 2,5-diaminobenzene-1,4-dithiol dihydrochloride or 2,5-diaminohydroquinone dihydrochloride under mild conditions, generating the desired COFs through the cascade cyclization and oxidation of the hydroxy-substituted imine bonds. The irreversible azole linkages empowered the modified COFs with remarkable stability under severe chemical conditions, such as in $10 \mathrm{M} \mathrm{NaOH}$ and $12.1 \mathrm{M} \mathrm{HCl}$ solutions.

Analogously, Lotsch and co-workers also transformed an imine-linked COF into a thiazole-linked COF through cascade oxidation-cyclisation (Fig. 8). ${ }^{71}$ The elemental sulfur oxidized aromatic imines to thioamides, followed by oxidative cyclization to form a thiazole ring. The final COF displayed enhanced chemical and electron beam stability, enabling investigation of the exact framework structure in great detail by electron diffraction and transmission electron microscopy. It is worth mentioning that this work revealed the structural features of 2D COFs including grain boundaries and edge dislocations. Very recently, Baek and co-workers also converted an imine-linked 

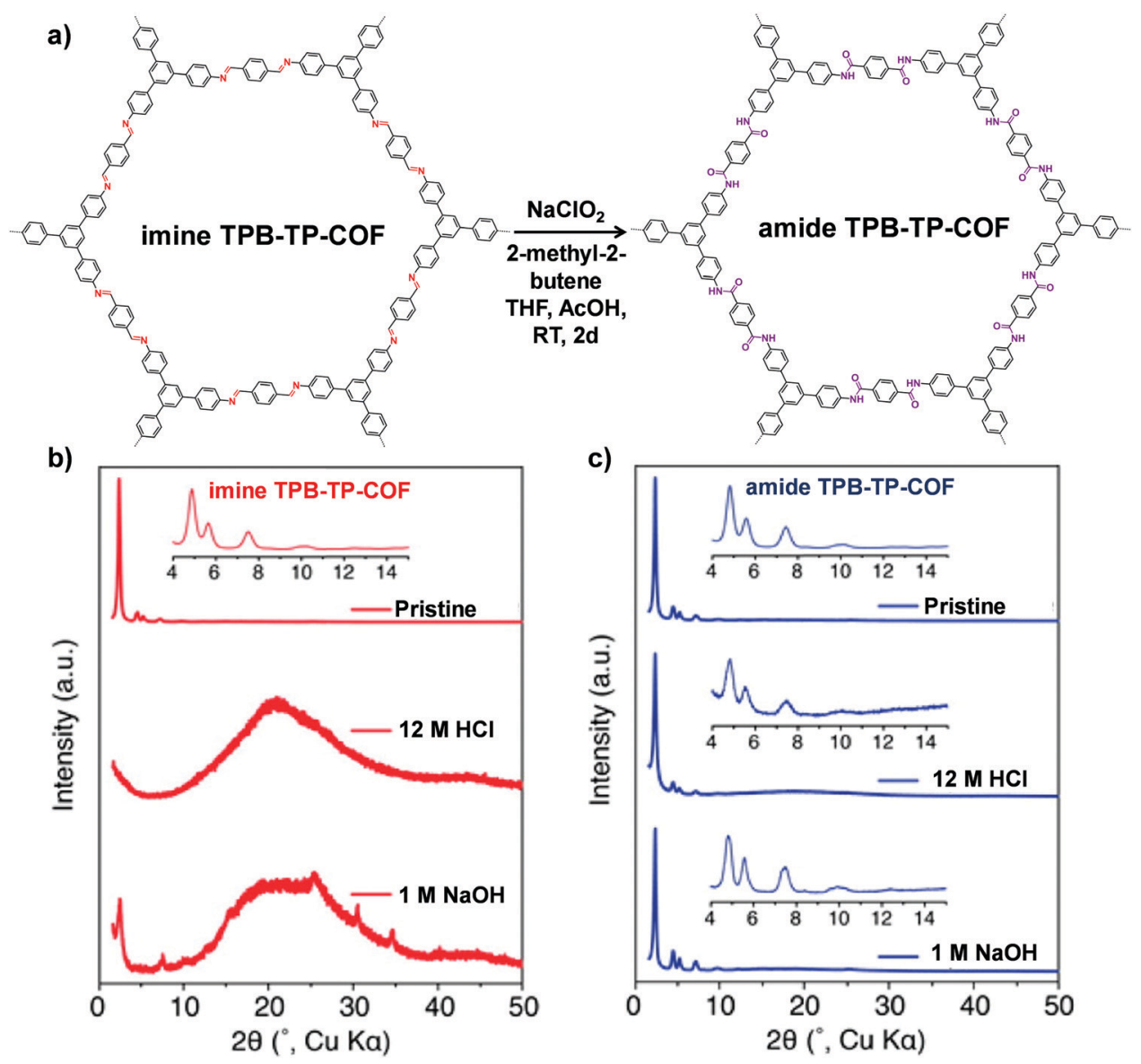

c)

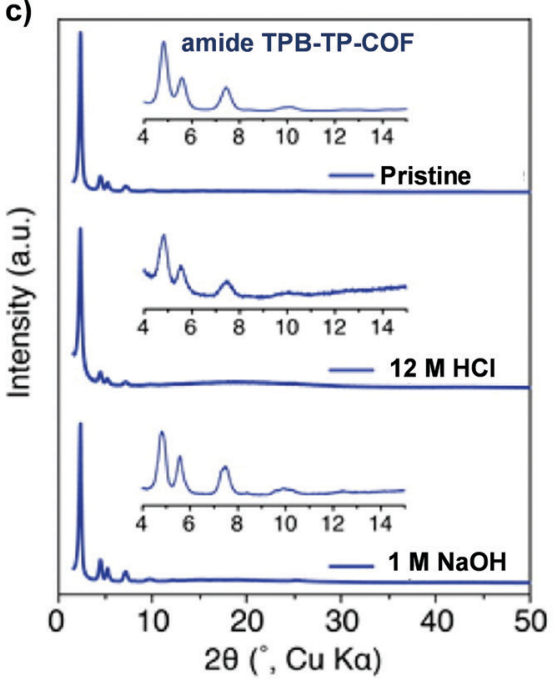

Fig. 6 (a) Conversion of imine TPB-TP-COF to amide TPB-TP-COF under oxidative reaction conditions. Comparison of diffraction patterns of imine TPB-TP-COF (b) and amide TPB-TP-COF (c) after $24 \mathrm{~h}$ treatment in solutions. Reproduced from ref. 67, with permission from American Chemical Society, Copyright 2016.

COF into a benzoxazole-linked COF via post-cyclization-oxidation. ${ }^{72}$ Due to the irreversibility of the benzoxazole linkage, the converted COF still retained high crystallinity and porosity even under $12 \mathrm{M} \mathrm{HCl(aq.)} \mathrm{and} 10 \mathrm{M} \mathrm{NaOH}($ aq.) conditions.

2.2.4. Sequential PSM of imine linkages. Very recently, Yaghi and co-workers developed a combination of linker modification and linkage transformations in three consecutive steps to convert an imine-linked 2D COF into cyclic carbamate and thiocarbamate-linked COFs. ${ }^{73}$ After deprotection reaction, followed by a reduction reaction, the resulting material undergoes further linkage modification with $1,1^{\prime}$-carbonyldiimidazole or $1,1^{\prime}$-thiocarbonyldiimidazole to give crystalline cyclic carbamate and thiocarbamate-linked COFs, respectively. The multistep PSM of the COF linkage represents significant progress in solid-state organic synthesis.

\section{Post-synthetic metal-functionalization}

COFs are the ideal candidates for metal-functionalization, because both the linkers and linkages consisting of electronegative elements such as $\mathrm{N}, \mathrm{O}, \mathrm{S}$ etc., can act as anchoring sites for metal binding. In a typical procedure, specific metallic units were incorporated into the as-prepared COFs by a coordination complexation reaction, affording metal-containing COFs with interesting properties. Based on the different probable interactions between metal ions and COF structures, the existing post-synthetic metal-functionalization methods can be classified into three classes: coordination with functional groups of linkers (a) or linkages (b) and post-synthetic demetallation or metal exchange (c).

\subsection{Post-synthetic metalation on organic linkers}

COFs with multidentated ligands such as porphyrin, bipyridine, $N, N^{\prime}$-bis(salicylidene)ethylenediamine (Salen) etc. can be utilized as matrices for metalation. In this section, we will focus on the post-synthetic metalation strategy of COFs possessing these linkers.

3.1.1. Porphyrin-based COFs. The most interesting feature of porphyrins is that they can coordinate with metal ions to form metalloporphyrins, bearing distinct photophysical and photochemical properties. ${ }^{74-77}$ Wang et al. reported the successful incorporation of $\mathrm{Zn}^{2+}$ and $\mathrm{Co}^{2+}$ into porphyrinbased COFs, which led to a different charge distribution and internal chemical environment. ${ }^{78}$ Using the same approach, the Marinescu group has achieved heterobimetallic COFs 
a)

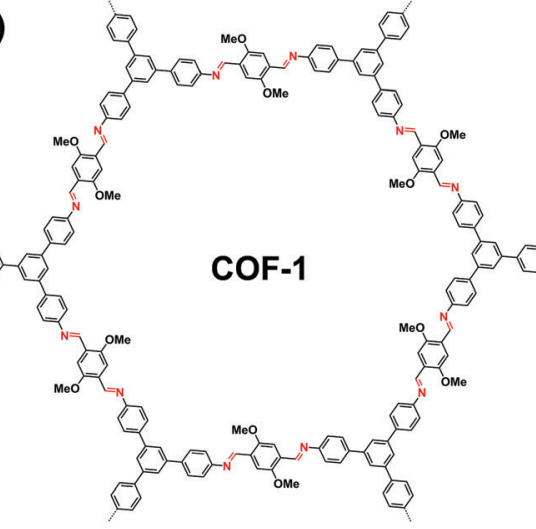

1b: $R=$ COOMe

1c: $R=F$

1d: $\mathrm{R}=\mathrm{CN}$

1e: $R=C_{3}$

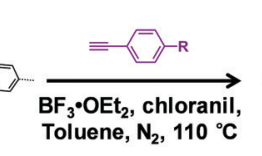

MF-1a: $\mathbf{R}=\mathbf{H}$ MF-1b: $R=$ COOMe

MF-1c: $R=F$

$M F-1 d: R=C N$

MF-1e: $R=\mathrm{CF}_{3}$

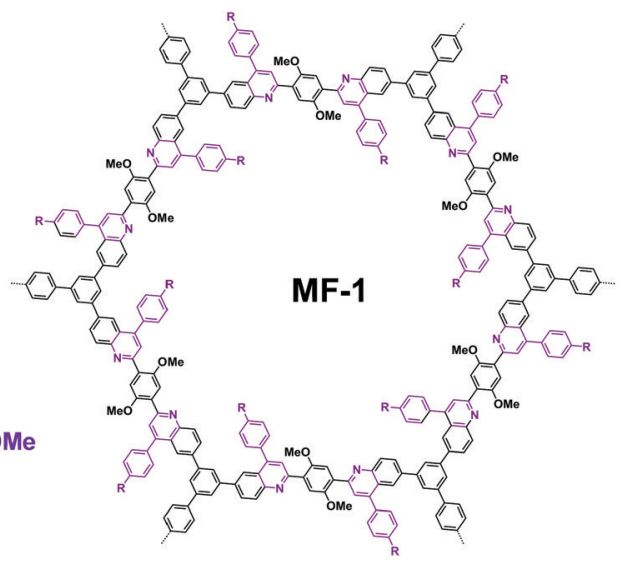

b)

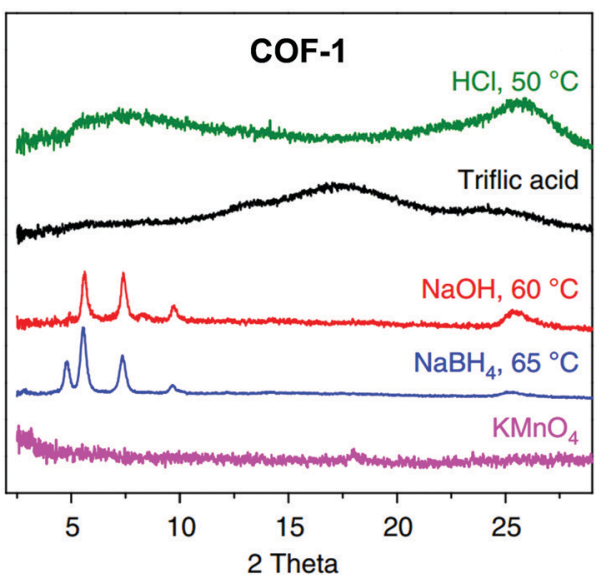

c)

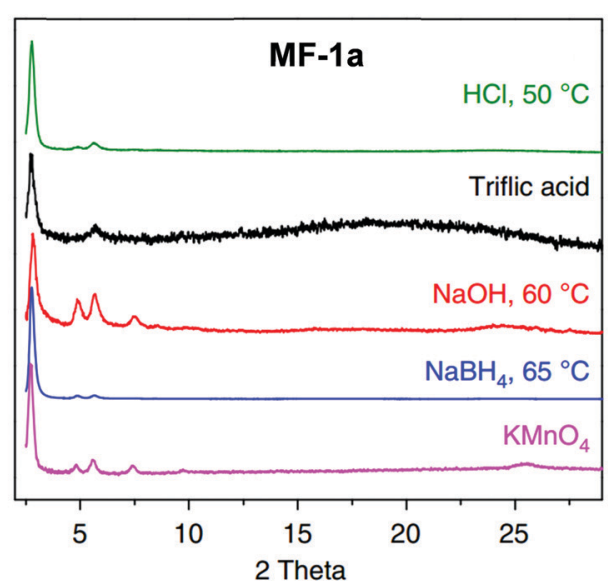

d)

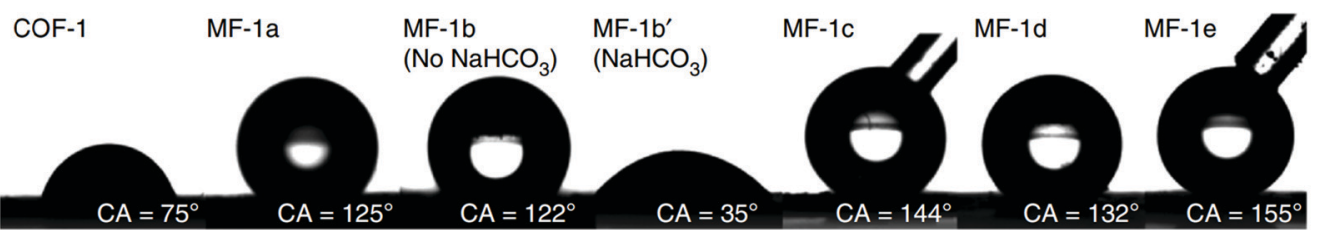

Fig. 7 (a) Synthesis of the imine-linked COF-1 to quinoline-linked MF-1 by aza-Diels-Alder cycloaddition reaction. PXRD patterns of COF-1 (b) and MF-1a (c) after treatment with different conditions. (d) Contact angles of water droplets on the pressed pellet of COF-1 and MF-1a-e. Reproduced from ref. 69, with permission from Springer Nature, Copyright 2018.

with excellent electrocatalytic activity in the reduction of $\mathrm{CO}_{2}$ to $\mathrm{CO}^{79}$

3.1.2. Bipyridine containing COFs. The integration of bipyridine ligands into COFs also offers an opportunity for post-metal-functionalization. Banerjee and co-workers have demonstrated the post-synthetic metalation of a highly stable bipyridine-containing COF (TpBpy) to produce a stable cobalt-modified COF (Co-TpBpy) (Fig. 9). ${ }^{80}$ Thermogravimetric analysis and the inductively coupled plasma data suggested that Co-TpBpy possessed a $\sim 12 \%$ cobalt content in the framework. They further investigated the catalytic performance of Co-TpBpy in an oxygen evolution reaction (OER). Consequently, this COF exhibited remarkable catalytic stability with retention of $94 \%$ OER activity even after 1000 cycles, which could be attributed to the synergy between inherent porosity and coordinating units in the framework.

Via a similar post-metalation process, Marinescu and co-workers successfully incorporated the rhenium(I) tricarbonyl fragments into a $\beta$-ketoenamine linked COF with the maintenance of crystallinity and porosity. ${ }^{81}$ In another report, Huang and co-workers have designed a photoactive COF hybrid upon onestep post-synthetic incorporation of tricarbonylchloro(bipyridyl)Re complex into a 2D triazine $\mathrm{COF}^{82}$ Recently, Cui and co-workers post-metalated $2,2^{\prime}$-bipyridine containing COFs to achieve metallobipyridyl COFs, which can be used as a heterogeneous catalyst in $\mathrm{C}-\mathrm{H}$ borylation of arenes. ${ }^{83}$

3.1.3. Salen-functionalized COFs. Salen functional units featuring excellent versatility in coordinating various metal ions have been proved to be an efficient catalyst in organic reactions. ${ }^{84}$ Wang et al. have constructed a series of metalloSalen-based COFs via post-metalation (Fig. 10). ${ }^{85}$ During the metalation of Salen-COF, the crystallinity was preserved as evident by PXRD patterns. As expected, the resulting M/Salen-COF displayed excellent heterogeneous catalytic activity in a Henry reaction. For instance, after five cycles, Co/Salen-COF can still retain over $75 \%$ of its initial performance. 

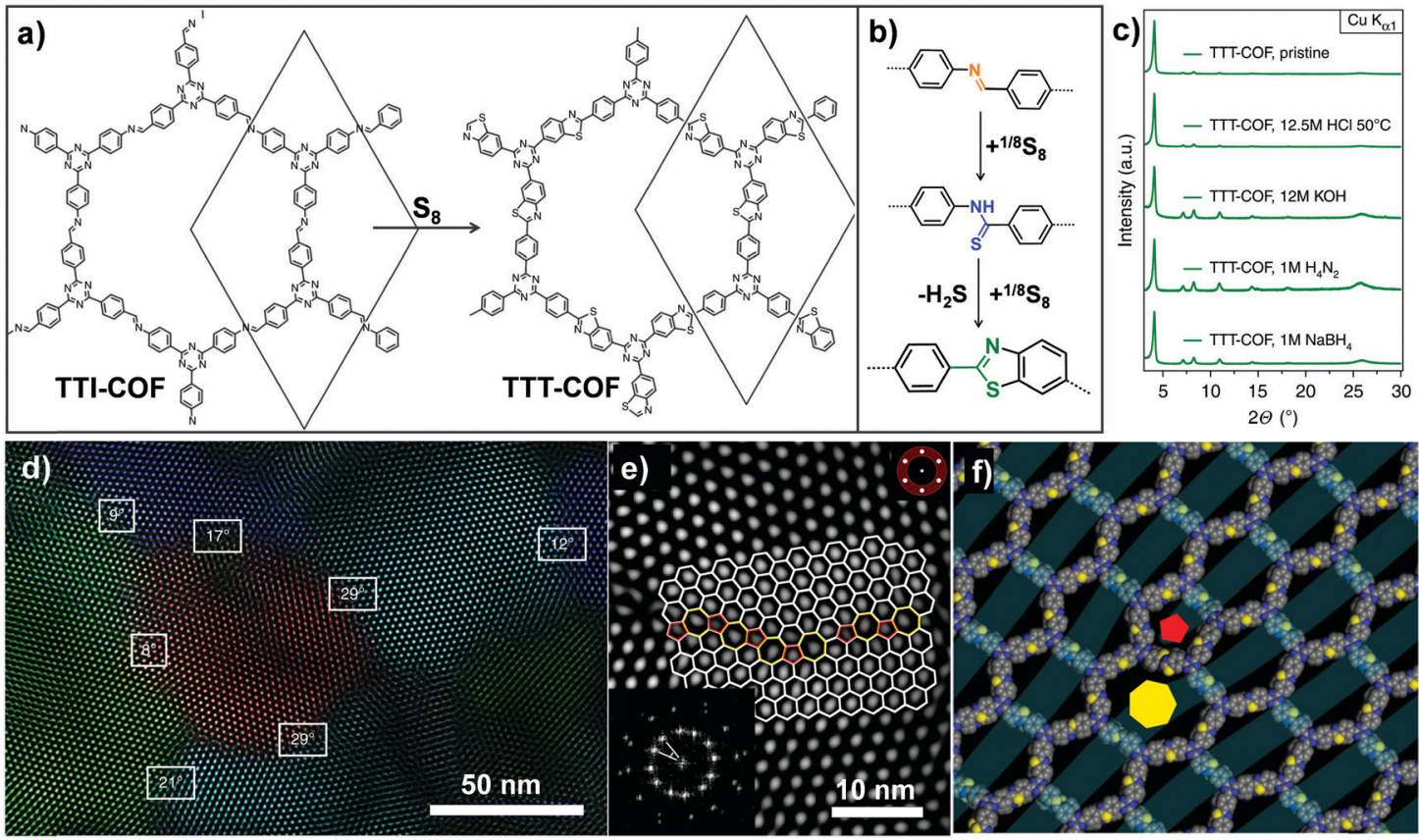

Fig. 8 (a) Post-synthetic transformation of the imine-linked TTI-COF to thiazole-linked TTT-COF. (b) Linkage transformation from imine to thioamide and to thiazole. (c) The TTT-COF samples were exposed to various conditions for $16 \mathrm{~h}$. (d) Grain boundaries and edge dislocations visible by TEM. (e) High angle grain boundary of crystallites showed the interface consisting of five, six and seven membered rings. (f) Modeling of dislocation along the pentagonal (red pentagon) and the heptagonal channel (yellow heptagon). Reproduced from ref. 71, with permission from Springer Nature, Copyright 2018.

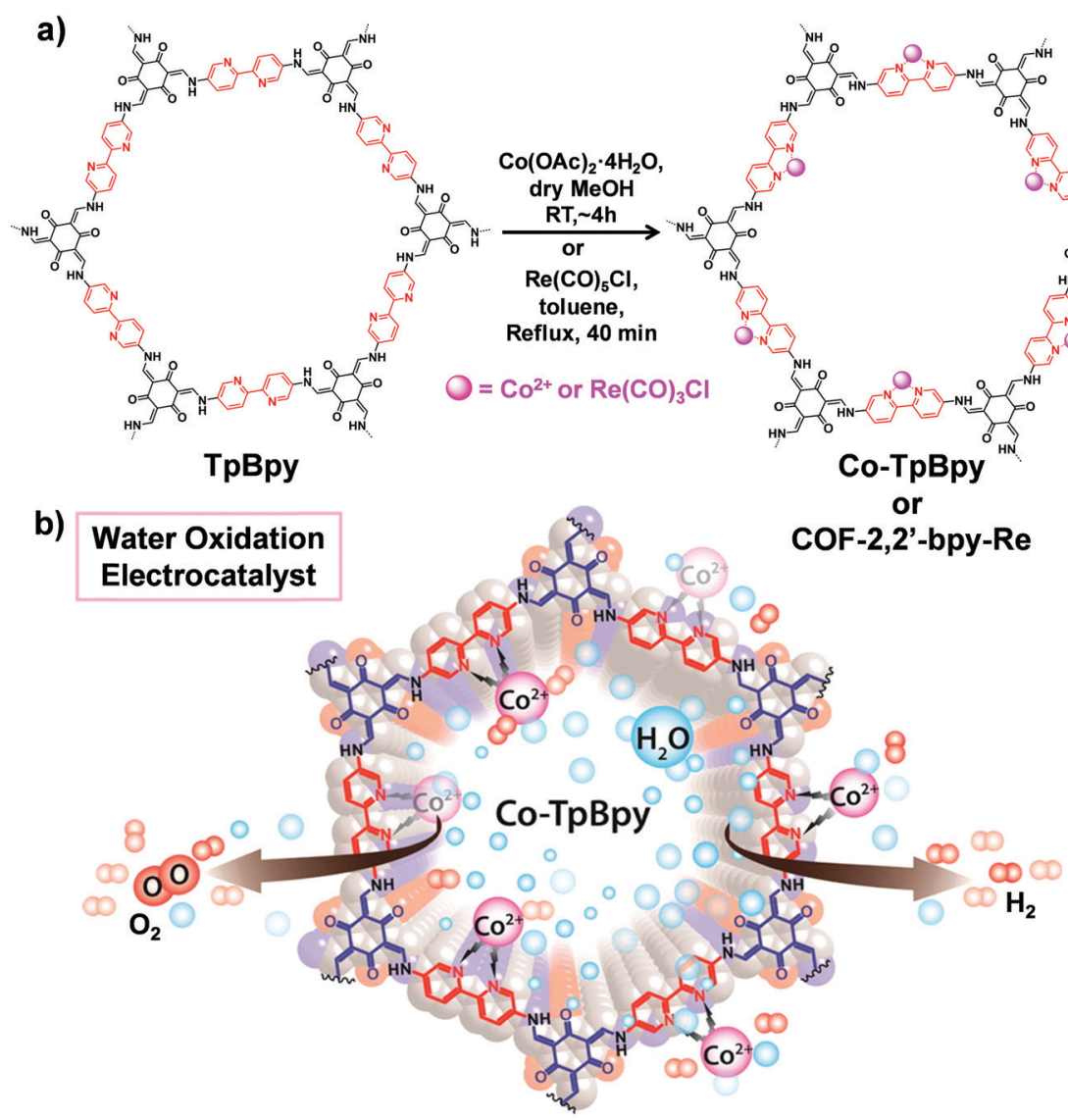

Fig. 9 (a) Post-synthetic metalation of TpBpy with cobalt and rhenium moieties to afford Co-TpBpy and COF-2,2'-bpy-Re, respectively. (b) Utilizing Co-TpBpy as an oxygen-evolving catalyst. Reproduced from ref. 80, with permission from American Chemical Society, Copyright 2016. 


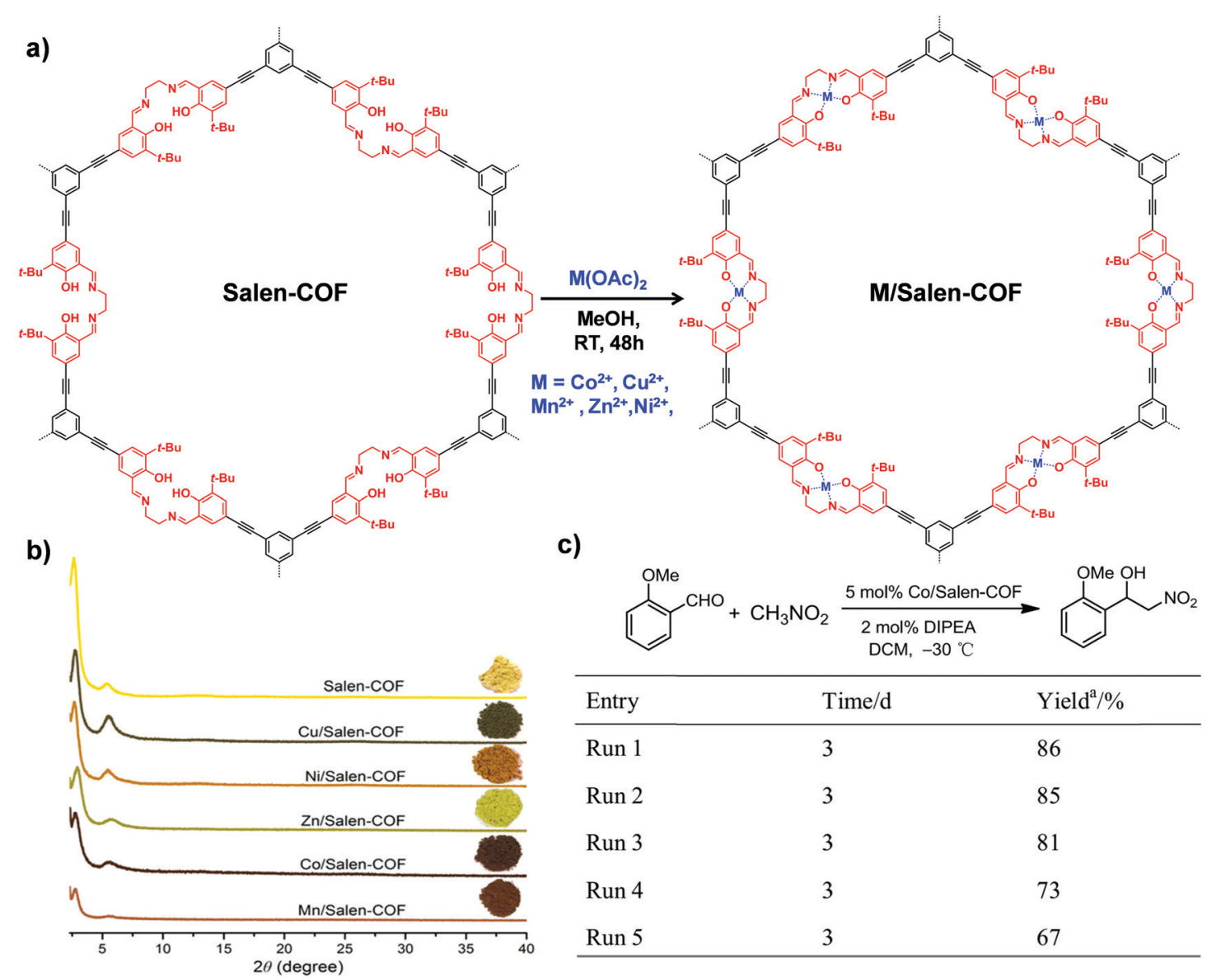

Fig. 10 (a) The synthesis of M/Salen-COF by post-metalation of Salen-COF with various metal acetates. (b) Comparison of the PXRD patterns and colors of Salen-COF and M/Salen-COF. (c) Recycling tests of Co/Salen-COF in a Henry reaction. Reproduced from ref. 85, with permission from American Chemical Society, Copyright 2017.

3.1.4. Dehydrobenzoannulene containing COFs. Dehydrobenzoannulenes (DBAs) are planar triangular shaped macrocycles that tend to form stable metal complexes with alkali metals and low-oxidation-state transition metals. ${ }^{86}$ In 2016, McGrier et al. synthesized a DBA containing 3D COF with high surface area $\left(S_{\mathrm{BET}}=5083 \mathrm{~m}^{2} \mathrm{~g}^{-1}\right) \cdot{ }^{87}$ Upon post-metalation with $\mathrm{Ni}(\mathrm{COD})_{2}$, the resulting COF with $10.1 \mathrm{wt} \%$ of Ni-loading still showed a high surface area $\left(S_{\mathrm{BET}}=4763 \mathrm{~m}^{2} \mathrm{~g}^{-1}\right)$. Moreover, the post-synthetic metalation of this COF slightly increased the absorption capacity of ethane and ethylene, which can be ascribed to the polarization effect and weak $\pi$-complexation in the presence of $\mathrm{Ni}(0)$ sites.

\subsection{Post-synthetic metalation with linkages}

The COF linkages, such as imine and hydrazine bonds, can bind to specific metal ions. Early in 2011, Wang et al. constructed Pd/COF-LZU1 via a simple post-synthetic metalation of imine-linked 2D COF (COF-LZU1) (Fig. 11). ${ }^{88}$ Owing to the

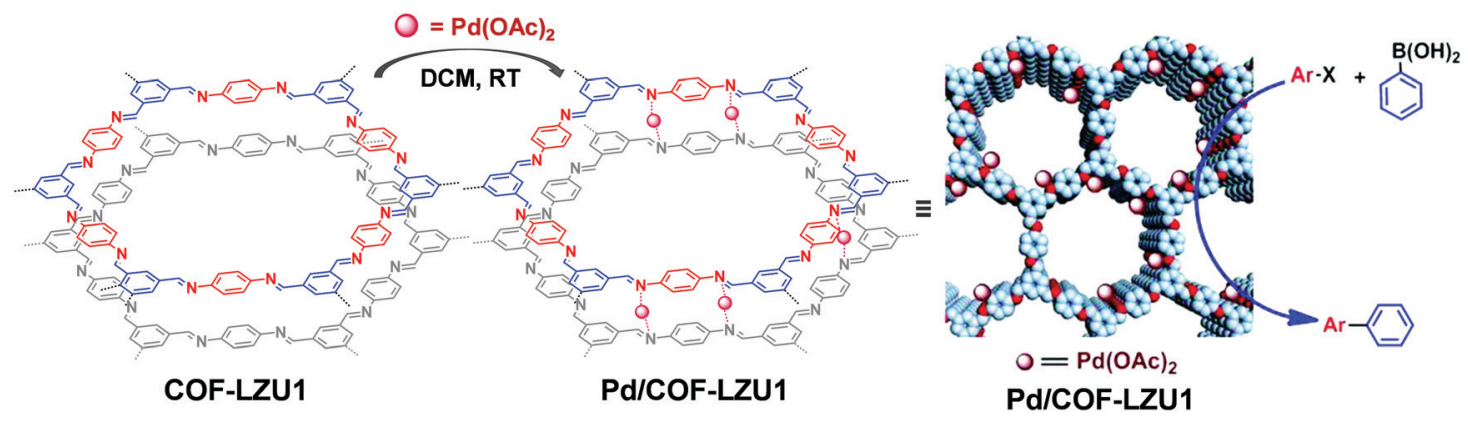

Fig. 11 Post-synthetic metalation of COF-LZU1 with $\mathrm{Pd}(\mathrm{OAC})_{2}$, the resulting Pd/COF-LZU1 was used as a catalyst in a Suzuki-Miyaura coupling reaction. Reproduced from ref. 88, with permission from American Chemical Society, Copyright 2011. 

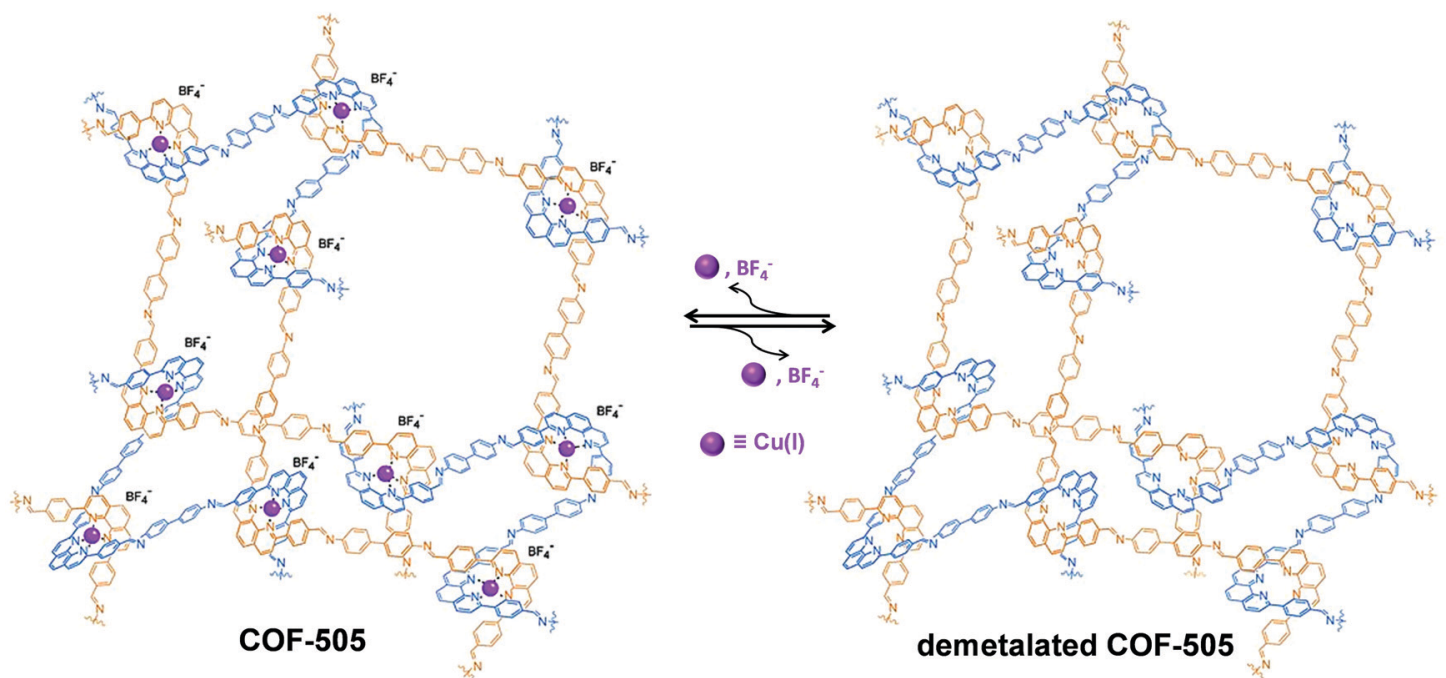

Fig. 12 Post-synthetic demetalation and remetalation of COF-505. Reproduced from ref. 93, with permission from The American Association for the Advancement of Science, Copyright 2016.

eclipsed and ordered $\pi$-columnar structures, the palladium metals were sandwiched between the adjacent COF layers and coordinated with the imine bonds. Interestingly, the resulting Pd/COF-LZU1 can be used as a catalyst in the Suzuki-Miyaura coupling reaction (Fig. 11). In the presence of $0.5 \mathrm{~mol} \%$ of Pd/COF-LZU1, the substituted aryl iodides afforded the cross-coupling products in high yields (96-98\%). After this seminal work, many other reports appeared where metal integrated COFs have been utilized in heterogeneous catalysis. ${ }^{89-91}$ For example, Chen and co-workers have reported the immobilization of copper salts into the Schiff base centers of an imine-linked 2D COF with hydroxyl functionalities. ${ }^{92}$

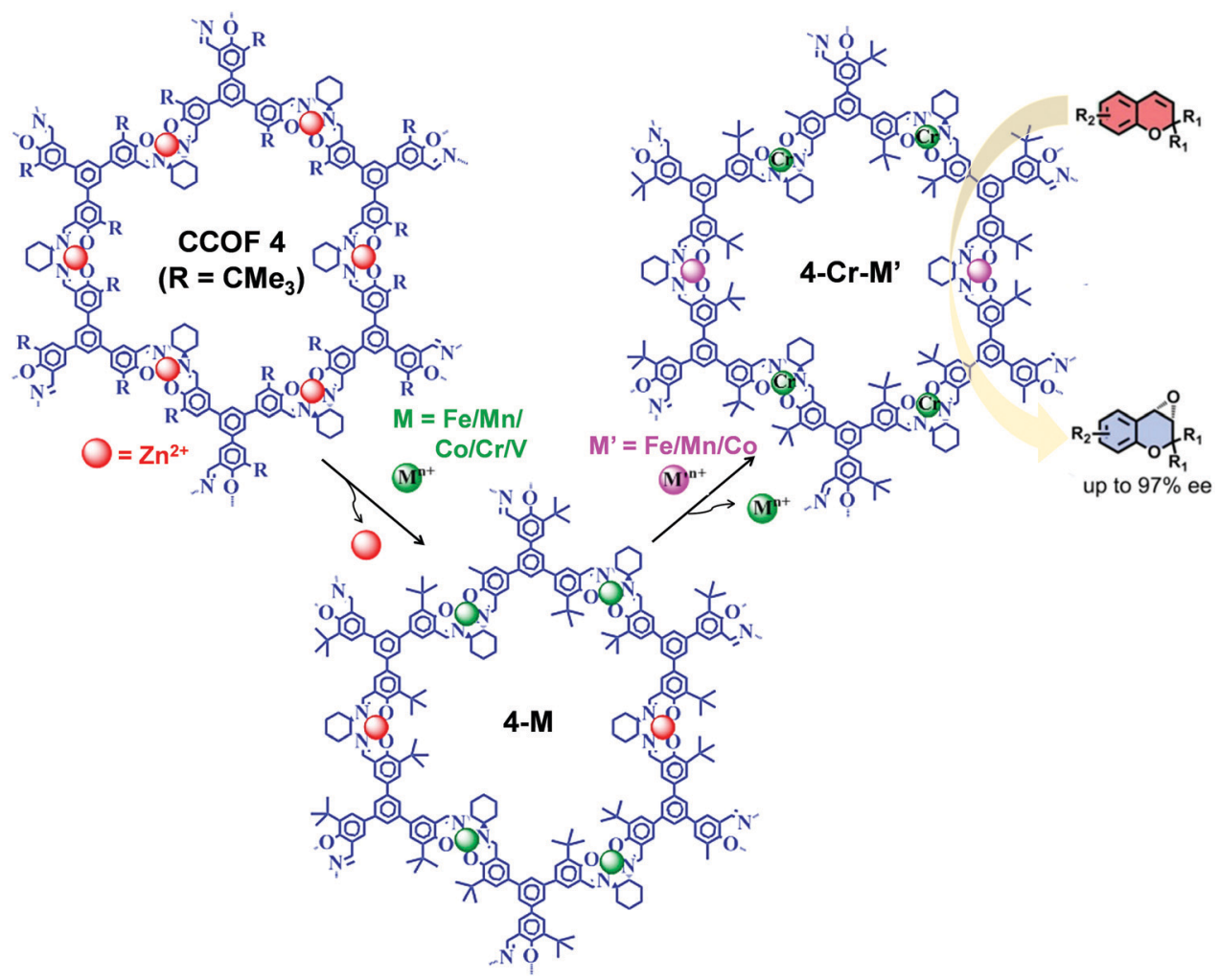

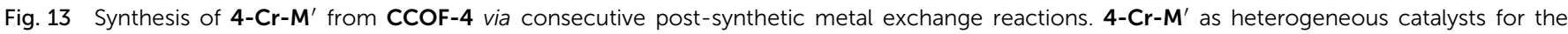
synthesis of amino-alcohol in sequential reactions starting from epoxidation reaction of alkene followed by ring-opening of epoxide. Reproduced from ref. 95, with permission from American Chemical Society, Copyright 2017. 
Interestingly, the copper-modified COF displayed good reusability and stability toward selective oxidation of styrene to benzaldehyde.

\subsection{Post-synthetic demetallation or metal exchange}

Similar to the post-synthetic deprotection strategy, post-synthetic demetallation involves the removal of metal ions from a metalated COF. Yaghi et al. have reported the construction of a 3D $\mathrm{Cu}(\mathrm{I})$ coordinated $\mathrm{COF}$ (COF-505), which can be demetalated by heating in a $\mathrm{KCN}$ solution (Fig. 12). ${ }^{93}$ Interestingly, upon removal of copper, the demetalated COF-505 showed more elastic properties with decreased effective Young's moduli of $1.3 \mathrm{GPa}$. It is worth mentioning that the metalation-demetalation and associated elasticity changes of COF-505 were found to be reversible upon reaction with $\mathrm{Cu}(\mathrm{I})$ ions.

The post-synthetic metal exchange, associated with demetalation $^{94}$ followed by remetalation with different metal ions, is another crucial PSM approach for COF functionalization. Recently, starting from Zn(salen) COF (CCOF-4), Cui et al. reported the construction of bimetallic $\mathrm{COF}\left(\mathbf{4}-\mathbf{C r}-\mathbf{M}^{\prime}\right)$ by two-step postsynthetic metal exchange (Fig. 13), which showed advantageous catalytic properties in several asymmetric transformations. ${ }^{95}$ In particular, in the epoxidation reaction of alkene followed by ring opening of epoxide to amino alcohol, 4-Cr-Mn exhibited better catalytic activity compared to $\mathbf{4}$-Cr.

\section{Conclusions and outlook}

Over the last decade, rapid progress has been witnessed in tailor-made functionalities and properties of COFs due to the emergence of various post-synthetic modification protocols. This review presents a comprehensive collection of the stateof-the-art PSM strategies for COF functionalization. We believe that in future, the vast array of both covalent chemical transformations and metal-functionalization protocols will offer an excellent opportunity for accessing COF materials with increased complexity and advanced functions.

Nevertheless, a large number of challenges need to be addressed in the field of functional exploration of COFs by PSM approaches. For example, vast post-synthetic options, including new methodologies and new reactions, remain to be further attempted. Apart from this, one vital point to be noted is the degree of post-synthetic conversion, which typically stays far from quantitative. Considering that the high concentration of functionalities in the COF framework endows them with superior performance, the next great challenge lies ahead to increase the contents of functional modules on the COF skeleton. Another issue to be looked at is the spatial location of the modified functional groups in COFs, as the functionalities present on the COF surface or the inside pores may result in different performances, especially in gas selectivity and catalytic activity. Thus, the exploration of functional group distributions in COFs is of great significance to establish the mechanistic pathways of adsorption or catalytic properties. Besides, PSM-programming for more complex multi-component COF architectures remains as the ultimate goal in order to realize the enormous potential of COFs in various fields. We still have a long way to go and an expanding research area in PSM of COFs for desired functionalities can be imagined.

\section{Conflicts of interest}

There are no conflicts to declare.

\section{Acknowledgements}

We gratefully acknowledge financial support from the National Natural Science Foundation of China (21772149, 21572170 and 21905212), the Funds for Creative Research Groups of Hubei Province (2017CFA002) and the Fundamental Research Funds for the Central Universities.

\section{References}

1 A. P. Cote, A. I. Benin, N. W. Ockwig, M. O'Keeffe, A. J. Matzger and O. M. Yaghi, Science, 2005, 310, 1166-1170. 2 Y. Jin, Y. Hu and W. Zhang, Nat. Rev. Chem., 2017, 1, 0056. 3 S.-L. Cai, K. Zhang, J.-B. Tan, S. Wang, S.-R. Zheng, J. Fan, Y. Yu, W.-G. Zhang and Y. Liu, ACS Macro Lett., 2016, 5, 1348-1352.

4 R.-R. Liang and X. Zhao, Org. Chem. Front., 2018, 5, 3341-3356.

5 F. Haase, K. Gottschling, L. Stegbauer, L. S. Germann, R. Gutzler, V. Duppel, V. S. Vyas, K. Kern, R. E. Dinnebier and B. V. Lotsch, Mater. Chem. Front., 2017, 1, 1354-1361.

6 C. Gao, J. Li, S. Yin, G. Lin, T. Ma, Y. Meng, J. Sun and C. Wang, Angew. Chem., Int. Ed., 2019, 58, 9770-9775.

7 T. Ma, E. A. Kapustin, S. X. Yin, L. Liang, Z. Zhou, J. Niu, L.-H. Li, Y. Wang, J. Su, J. Li, X. Wang, W. D. Wang, W. Wang, J. Sun and O. M. Yaghi, Science, 2018, 361, 48-52.

8 X. Ma and T. F. Scott, Chem. Commun., 2018, 1, 98.

9 Y.-B. Zhang, J. Su, H. Furukawa, Y. Yun, F. Gandara, A. Duong, X. Zou and O. M. Yaghi, J. Am. Chem. Soc., 2013, 135, 16336-16339.

10 H. M. El-Kaderi, J. R. Hunt, J. L. Mendoza-Cortes, A. P. Cote, R. E. Taylor, M. O'Keeffe and O. M. Yaghi, Science, 2007, 316, 268-272.

11 H. Fan, A. Mundstock, A. Feldhoff, A. Knebel, J. Gu, H. Meng and J. Caro, J. Am. Chem. Soc., 2018, 140, 10094-10098.

12 Y. Zeng, R. Zou and Y. Zhao, Adv. Mater., 2016, 28, 2855-2873.

13 H. Furukawa and O. M. Yaghi, J. Am. Chem. Soc., 2009, 131, 8875-8883.

14 S. Yan, X. Guan, H. Li, D. Li, M. Xue, Y. Yan, V. Valtchev, S. Qiu and Q. Fang, J. Am. Chem. Soc., 2019, 141, 2920-2924.

15 L. Stegbauer, K. Schwinghammer and B. V. Lotsch, Chem. Sci., 2014, 5, 2789-2793.

16 S. Lin, C. S. Diercks, Y.-B. Zhang, N. Kornienko, E. M. Nichols, Y. Zhao, A. R. Paris, D. Kim, P. Yang, O. M. Yaghi and C. J. Chang, Science, 2015, 349, 1208-1213.

17 Q. Sun, B. Aguila and S. Ma, Mater. Chem. Front., 2017, 1, 1310-1316.

18 Q. Gao, X. Li, G.-H. Ning, K. Leng, B. Tian, C. Liu, W. Tang, H.-S. Xu and K. P. Loh, Chem. Commun., 2018, 54, 2349-2352. 
19 G. Lin, H. Ding, D. Yuan, B. Wang and C. Wang, J. Am. Chem. Soc., 2016, 138, 3302-3305.

20 R. Xue, H. Guo, T. Wang, L. Gong, Y. Wang, J. Ai, D. Huang, H. Chen and W. Yang, Anal. Methods, 2017, 9, 3737-3750.

21 L. Ma, X. Feng, S. Wang and B. Wang, Mater. Chem. Front., 2017, 1, 2474-2486.

22 S.-Y. Ding, M. Dong, Y.-W. Wang, Y.-T. Chen, H.-Z. Wang, C.-Y. Su and W. Wang, J. Am. Chem. Soc., 2016, 138, 3031-3037.

23 M. Dogru and T. Bein, Chem. Commun., 2014, 50, 5531-5546.

24 D. D. Medina, T. Sick and T. Bein, Adv. Energy Mater., 2017, 7, 1700387.

25 H. Ding, J. Li, G. Xie, G. Lin, R. Chen, Z. Peng, C. Yang, B. Wang, J. Sun and C. Wang, Nat. Commun., 2018, 9, 5234.

26 S. Wan, J. Guo, J. Kim, H. Ihee and D. Jiang, Angew. Chem., Int. Ed., 2009, 48, 5439-5442.

27 X. Meng, H.-N. Wang, S.-Y. Song and H.-J. Zhang, Chem. Soc. Rev., 2017, 46, 464-480.

28 Z. Meng, A. Aykanat and K. A. Mirica, Chem. Mater., 2019, 31, 819-825.

29 C. Montoro, D. Rodriguez-San-Miguel, E. Polo, R. EscuderoCid, M. Luisa Ruiz-Gonzalez, J. A. R. Navarro, P. Ocon and F. Zamora, J. Am. Chem. Soc., 2017, 139, 10079-10086.

30 C.-Y. Lin, D. Zhang, Z. Zhao and Z. Xia, Adv. Mater., 2018, 30, 1703646.

31 X. Zhan, Z. Chen and Q. Zhang, J. Mater. Chem. A, 2017, 5, 14463-14479.

32 S. Wang, Q. Wang, P. Shao, Y. Han, X. Gao, L. Ma, S. Yuan, X. Ma, J. Zhou, X. Feng and B. Wang, J. Am. Chem. Soc., 2017, 139, 4258-4261.

33 H. Liao, H. Wang, H. Ding, X. Meng, H. Xu, B. Wang, X. Ai and C. Wang, J. Mater. Chem. A, 2016, 4, 7416-7421.

34 V. Valtchev, G. Majano, S. Mintova and J. Perez-Ramirez, Chem. Soc. Rev., 2013, 42, 263-290.

35 J. L. Segura, S. Royuela and M. Mar Ramos, Chem. Soc. Rev., 2019, 48, 3903-3945.

36 Y. Yusran, Q. Fang and S. Qiu, Isr. J. Chem., 2018, 58, 971-984.

37 H. C. Kolb, M. G. Finn and K. B. Sharpless, Angew. Chem., Int. Ed., 2001, 40, 2004-2021.

38 A. Nagai, Z. Guo, X. Feng, S. Jin, X. Chen, X. Ding and D. Jiang, Nat. Commun., 2011, 2, 536.

39 L. Chen, K. Furukawa, J. Gao, A. Nagai, T. Nakamura, Y. Dong and D. Jiang, J. Am. Chem. Soc., 2014, 136, 9806-9809.

40 H. Xu, J. Gao and D. Jiang, Nat. Chem., 2015, 7, 905-912.

41 A. M. Rice, E. A. Dolgopolova, B. J. Yarbrough, G. A. Leith, C. R. Martin, K. S. Stephenson, R. A. Heugh, A. J. Brandt, D. A. Chen, S. G. Karakalos, M. D. Smith, K. B. Hatzell, P. J. Pellechia, S. Garashchuk and N. B. Shustova, Angew. Chem., Int. Ed., 2018, 57, 11310-11315.

42 D. N. Bunck and W. R. Dichtel, Chem. Commun., 2013, 49, 2457-2459.

43 Q. Sun, B. Aguila, J. Perman, L. D. Earl, C. W. Abney, Y. Cheng, H. Wei, N. Nguyen, L. Wojtas and S. Ma, J. Am. Chem. Soc., 2017, 139, 2786-2793.

44 Q. Sun, B. Aguila, J. A. Perman, T. Butts, F.-S. Xiao and S. Ma, Chem, 2018, 4, 1726-1739.
45 N. Huang, X. Chen, R. Krishna and D. Jiang, Angew. Chem., Int. Ed., 2015, 54, 2986-2990.

46 Q. Lu, Y. Ma, H. Li, X. Guan, Y. Yusran, M. Xue, Q. Fang, Y. Yan, S. Qiu and V. Valtchev, Angew. Chem., Int. Ed., 2018, 57, 6042-6048.

47 S. Zhao, B. Dong, R. Ge, C. Wang, X. Song, W. Ma, Y. Wang, C. Hao, X. Guo and Y. Gao, RSC Adv., 2016, 6, 38774-38781.

48 H. Hu, Q. Yan, M. Wang, L. Yu, W. Pan, B. Wang and Y. Gao, Chin. J. Catal., 2018, 39, 1437-1444.

49 B. Dong, L. Wang, S. Zhao, R. Ge, X. Song, Y. Wang and Y. Gao, Chem. Commun., 2016, 52, 7082-7085.

50 S. Rager, M. Dogru, V. Werner, A. Gavryushin, M. Goetz, H. Engelke, D. D. Medina, P. Knochel and T. Bein, CrystEngComm, 2017, 19, 4886-4891.

51 B. Zhang, M. Wei, H. Mao, X. Pei, S. A. Alshmimri, J. A. Reimer and O. M. Yaghi, J. Am. Chem. Soc., 2018, 140, 12715-12719.

52 Q. Sun, B. Aguila, L. D. Earl, C. W. Abney, L. Wojtas, P. K. Thallapally and S. Ma, Adv. Mater., 2018, 30, 1705479.

53 D. Becker, B. P. Biswal, P. Kalenczuk, N. Chandrasekhar, L. Giebeler, M. Addicoat, S. Paasch, E. Brunner, K. Leo, A. Dianat, G. Cuniberti, R. Berger and X. Feng, Chem. - Eur. J., 2019, 25, 6562-6568.

54 M. S. Lohse, T. Stassin, G. Naudin, S. Wuttke, R. Ameloot, D. De Vos, D. D. Medina and T. Bein, Chem. Mater., 2016, 28, 626-631.

55 M. A. Khayum, S. Kandambeth, S. Mitra, S. B. Nair, A. Das, S. S. Nagane, R. Mukherjee and R. Banerjee, Angew. Chem., Int. Ed., 2016, 55, 15604-15608.

56 Y. Wu, Z. Zhang, S. Bandow and K. Awaga, Bull. Chem. Soc. Jpn., 2017, 90, 1382-1387.

57 S. Royuela, J. Almarza, M. J. Mancheno, J. C. Perez-Flores, E. G. Michel, M. M. Ramos, F. Zamora, P. Occon and J. L. Segura, Chem. - Eur. J., 2019, 25, 12394-12404.

58 Q. Jiang, Y. Li, X. Zhao, P. Xiong, X. Yu, Y. Xu and L. Chen, J. Mater. Chem. A, 2018, 6, 17977-17981.

59 H.-S. Xu, S.-Y. Ding, W.-K. An, H. Wu and W. Wang, J. Am. Chem. Soc., 2016, 138, 11489-11492.

60 J. Zhang, X. Han, X. Wu, Y. Liu and Y. Cui, J. Am. Chem. Soc., 2017, 139, 8277-8285.

61 H.-L. Qian, Y. Li and X.-P. Yan, J. Mater. Chem. A, 2018, 6, 17307-17311.

62 G. Zhang, M. Tsujimoto, D. Packwood, D. Nghia Tuan, Y. Nishiyama, K. Kadota, S. Kitagawa and S. Horike, J. Am. Chem. Soc., 2018, 140, 2602-2609.

63 M. C. Daugherty, E. Vitaku, R. L. Li, A. M. Evans, A. D. Chavez and W. R. Dichtel, Chem. Commun., 2019, 55, 2680-2683.

64 Z. Miao, G. Liu, Y. Cui, Z. Liu, J. Li, F. Han, Y. Liu, X. Sun, X. Gong, Y. Zhai, Y. Zhao and Y. Zeng, Angew. Chem., Int. Ed., 2019, 58, 4906-4910.

65 C. Qian, Q.-Y. Qi, G.-F. Jiang, F.-Z. Cui, Y. Tian and X. Zhao, J. Am. Chem. Soc., 2017, 139, 6736-6743.

66 Z. Li, X. Ding, Y. Feng, W. Feng and B.-H. Han, Macromolecules, 2019, 52, 1257-1265.

67 P. J. Waller, S. J. Lyle, T. M. O. Popp, C. S. Diercks, J. A. Reimer and O. M. Yaghi, J. Am. Chem. Soc., 2016, 138, 15519-15522. 
68 X. Hang, J. Huang, C. Yuan, Y. Liu and Y. Cui, J. Am. Chem. Soc., 2018, 140, 892-895.

69 X. Li, C. Zhang, S. Cai, X. Lei, V. Altoe, F. Hong, J. J. Urban, J. Ciston, E. M. Chan and Y. Liu, Nat. Commun., 2018, 9, 2998.

70 P. J. Waller, Y. S. AlFaraj, C. S. Diercks, N. N. Jarenwattananon and O. M. Yaghi, J. Am. Chem. Soc., 2018, 140, 9099-9103.

71 F. Haase, E. Troschke, G. Savasci, T. Banerjee, V. Duppel, S. Doerfler, M. M. J. Grundei, A. M. Burow, C. Ochsenfeld, S. Kaskel and B. V. Lotsch, Nat. Commun., 2018, 9, 2600.

72 J.-M. Seo, H.-J. Noh, H. Y. Jeong and J.-B. Baek, J. Am. Chem. Soc., 2019, 141, 11786-11790.

73 S. J. Lyle, T. M. O. Popp, P. J. Waller, X. Pei, J. A. Reimer and O. M. Yaghi, J. Am. Chem. Soc., 2019, 141, 11253-11258.

74 K. S. Suslick, P. Bhyrappa, J. H. Chou, M. E. Kosal, S. Nakagaki, D. W. Smithenry and S. R. Wilson, Acc. Chem. Res., 2005, 38, 283-291.

75 G. M. Eder, D. A. Pyles, E. R. Wolfson and P. L. McGrier, Chem. Commun., 2019, 55, 7195-7198.

76 N. Keller, M. Calik, D. Sharapa, H. R. Soni, P. M. Zehetmaier, S. Rager, F. Auras, A. C. Jakowetz, A. Goerling, T. Clark and T. Bein, J. Am. Chem. Soc., 2018, 140, 16544-16552.

77 G. Lin, H. Ding, R. Chen, Z. Peng, B. Wang and C. Wang, J. Am. Chem. Soc., 2017, 139, 8705-8709.

78 K. Xu, Y. Dai, B. Ye and H. Wang, Dalton Trans., 2017, 46, 10780-10785.

79 E. M. Johnson, R. Haiges and S. C. Marinescu, ACS Appl. Mater. Interfaces, 2018, 10, 37919-37927.

80 H. B. Aiyappa, J. Thote, D. B. Shinde, R. Banerjee and S. Kurungot, Chem. Mater., 2016, 28, 4375-4379.

81 D. A. Popov, J. M. Luna, N. M. Orchanian, R. Haiges, C. A. Downes and S. C. Marinescu, Dalton Trans., 2018, 47, 17450-17460.
82 S. Yang, W. Hu, X. Zhang, P. He, B. Pattengale, C. Liu, M. Cendejas, I. Hermans, X. Zhang, J. Zhang and J. Huang, J. Am. Chem. Soc., 2018, 140, 14614-14618.

83 X. Wu, X. Han, Y. Liu, Y. Liu and Y. Cui, J. Am. Chem. Soc., 2018, 140, 16124-16133.

84 C. Baleizao and H. Garcia, Chem. Rev., 2006, 106, 3987-4043.

85 L.-H. Li, X.-L. Feng, X.-H. Cui, Y.-X. Ma, S.-Y. Ding and W. Wang, J. Am. Chem. Soc., 2017, 139, 6042-6045.

86 J. W. Crowe, L. A. Baldwin and P. L. McGrier, J. Am. Chem. Soc., 2016, 138, 10120-10123.

87 L. A. Baldwin, J. W. Crowe, D. A. Pyles and P. L. McGrier, J. Am. Chem. Soc., 2016, 138, 15134-15137.

88 S.-Y. Ding, J. Gao, Q. Wang, Y. Zhang, W.-G. Song, C.-Y. Su and W. Wang, J. Am. Chem. Soc., 2011, 133, 19816-19822.

89 T. Banerjee, F. Haase, G. Savasci, K. Gottschling, C. Ochsenfeld and B. V. Lotsch, J. Am. Chem. Soc., 2017, 139, 16228-16234.

90 L. Chen, L. Zhang, Z. Chen, H. Liu, R. Luque and Y. Li, Chem. Sci., 2016, 7, 6015-6020.

91 J. Romero, D. Rodriguez-San-Miguel, A. Ribera, R. Mas-Ballesté, T. F. Otero, I. Manet, F. Licio, G. Abellán, F. Zamora and E. Coronado, J. Mater. Chem. A, 2017, 5, 4343-4351.

92 M. Mu, Y. Wang, Y. Qin, X. Yan, Y. Li and L. Chen, ACS Appl. Mater. Interfaces, 2017, 9, 22856-22863.

93 Y. Liu, Y. Ma, Y. Zhao, X. Sun, F. Gandara, H. Furukawa, Z. Liu, H. Zhu, C. Zhu, K. Suenaga, P. Oleynikov, A. S. Alshammari, X. Zhang, O. Terasaki and O. M. Yaghi, Science, 2016, 351, 365-369.

94 Y. Liu, C. S. Diercks, Y. Ma, H. Lyu, C. Zhu, S. A. Alshmimri, S. Alshihri and O. M. Yaghi, J. Am. Chem. Soc., 2019, 141, 677-683.

95 X. Han, Q. Xia, J. Huang, Y. Liu, C. Tan and Y. Cui, J. Am. Chem. Soc., 2017, 139, 8693-8697. 